\title{
Air Cargo beyond Trade Barriers in Africa
}

\author{
Bianka Dettmer \\ Friedrich Schiller University Jena, Jena, Germany \\ Andreas Freytag \\ Friedrich Schiller University Jena, Jena, Germany and Stellenbosch University, South Africa \\ Peter Draper \\ South African Institute of International Affairs, Johannesburg, South Africa
}

\begin{abstract}
We develop a methodology based on two important criteria - sensitivity in delivery time and value-to-weight ratio - to classify air cargo products. The classification is applied to evaluate the trade integration in Southern Africa since air cargo is a valuable option to overcome trade barriers associated with poor land transport infrastructure and corruption. We find that South Africa's exports to industrialized countries consist of precious products such as diamonds and gold. These products tend to be transported in the hand baggage of a security personnel as they leave the loading weight of an average airplane almost unaffected. When correcting African trade for these 'invisible outliers' in the loading freight, we find that African trade integration including Southern Africa is based upon a comparatively higher share of air cargo relevant products than Southern Africa's trade with industrialized and emerging economies. A more liberal market for air cargo services can reduce transport costs and will allow the continent to integrate even further.
\end{abstract}

JEL Classifications: F10, F14, F15, L93

Key words: Trade Cost, Time Sensitivity, Air Cargo Transport, Intra-African Trade Integration

\footnotetext{
* Corresponding Author: Bianka Dettmer; Friedrich Schiller University Jena, Carl-Zeiss-Str. 3, 07743 Jena, Germany; Tel: +49 3641943256, Fax: +49 3641943252, E-mail: bianka.dettmer@uni-jena.de.

Co-Author: : Andreas Freytag; Friedrich Schiller University Jena, Carl-Zeiss-Str. 3, 07743 Jena, Germany; Tel: +49 3641943250, Fax: +49 3641943252, E-mail: andreas.freytag@uni-jena.de,

Peter Draper; South African Institute of International Affairs, P.O. Box 31596, Braamfontein, 2017 Johannesburg, South Africa; Tel: +27 113392021161, Fax: +27 113392154, E-mail: peter.draper@saiia.org.za.
} 


\section{Introduction}

South Africa can be regarded as a small open economy. Since the end of Apartheid, its foreign trade has increased substantially, not least because of its expanding international relations. It can be expected that - given the growth potential of South Africa and its African peers in the Southern African Development Community (SADC) - trade will increase substantially in the coming years. In particular, trade within the African continent is promising at the beginning of the $21^{\text {st }}$ century. This holds all the more as South Africa's trade with the rest of Africa today still plays a minor role in the country's trade profile, especially when compared to its trade with Europe and other industrialized countries. There is much potential to be exploited in the African continent.

To deal with future trade flows, policymakers and private investors have to make very sensitive decisions today. This is especially relevant since the intra-African transportation infrastructure is rather poor, both absolutely and relatively, in comparison with that of other continents. This makes trade within the continent rather expensive and cumbersome. This problem is magnified by a high prevalence of cross-border barriers which are associated not only with monetary transport costs but also with time costs, e.g. the delivery time caused by the poor transport network, high administrative requirements, and corruption problems at seaports and in general, leading to utilizing air cargo transport.

The previous literature on time costs and modal choice of transport has largely focused on time-sensitivity in the delivery of certain products. In this paper we develop a framework to systematically classify air cargo relevant products. This classification builds upon two important criteria: the time-sensitivity and the value-to-weight ratio of products. The argument behind this classification scheme is that in addition to delivery time the air premium, i.e. the additional cost of shipping via air instead of sea, is an important determinant to choose air transport. For precious products with a high valueto-weight ratio the transport costs and the air premium becomes vanishingly small relative to the value of the product so that time sensitivity is not the primary determinant of the choice to employ air transport. For example, diamonds, gold, and platinum have outstanding value-to-weight ratios and are among the main export products of South Africa. However, other products with a relatively low value-to-weight ratio, for example fruits and vegetables, can be transported via air cargo due to their low storage 
life and, thus, time-sensitivity. For these products the air premium becomes a much more important determinant when choosing the mode of transport.

Since it is almost impossible to find detailed data about intra-African air transport, we make use of a large database provided by the European Statistical Office, which includes value and volume data by product and mode of transport. The European Union is by far South Africa's largest trading partner and absorbs almost 26 per cent of its exports and, in this respect, covers the trade structure of South Africa substantially. The data are used, first, to evaluate the loading of an average airplane between South Africa and the European Union in the period of 2005 to 2010, and second, to derive average value-to-weight ratios and time-sensitivity measures at the product level. Based on these two measures, products are then classified into four groups ranging from the nonair cargo relevant group to the group consisting of products with the highest probability of being shipped via air cargo.

This product classification is used to evaluate the prospects for air cargo transport in Southern Africa. We find that especially the export of products with high and medium air cargo relevance has grown much faster than exports of bulky goods and nonair cargo products. South Africa's most prominent export products to industrialized countries consist of diamonds, gold, and platinum (HS71), which account for 17 per cent of total export value. However, these products have little effect on the loading weight of the average airplane. It seems that these 'invisible outliers' are so precious that they tend to be transported in the hand baggage of business or security personnel. When correcting South Africa's trade for these 'invisible outliers' in loading freight we find that South Africa exports a much larger share of products with high air cargo relevance to its SADC partners (i.e. Zambia, Zimbabwe, and Mozambique) than to industrialized countries (i.e. EU, US, and Japan). Given these results, air cargo transport seems to be a valuable option to overcome trade barriers associated with infrastructure and corruption.

This paper is structured as follows. The following section gives a short review of the literature with respect to trade costs and explains the determinants of the modal choice of transport. In the third section we present the methodology and data used to classify products relevant to air transport. Section IV discusses the results with respect to the potential of intra-African air cargo transport. The last section concludes the paper. 


\section{Literature Review}

The sources of Africa's marginal participation in world trade are widely debated (Amjadi et al. 1996) and include a comparative advantage in primary products (Wood and Mayer 2001), inadequate income growth, poor geography (Rodrik 1997), high domestic barriers to international trade ( $\mathrm{Ng}$ and Yeats 1996), and high transport costs associated with infrastructure (Limao and Venables 2001, Elbadawi 2001). Hummels (2001) is a seminal contribution to the idea that time is a trade barrier in itself. He argues that delivery time determines the probability to enter a market and the volume of trade when market entry is chosen. From a theoretical perspective, lengthy shipping times impose inventory holding costs (e.g. the capital costs of goods when in transit and the need to hold buffer stocks to accommodate variation in arrival time) and depreciation costs. For example, fresh products or cut flowers, items with immediate information content (e.g. newspaper, documents and mail, and personal computers) as well as goods with characteristics for which demand or the 'ideal types' cannot be forecasted well in advance (e.g. toys and high fashion apparel) are to a higher extent sensitive with respect to delivery time. Hummels and Schaur (2010) build upon the argument by Aizenman (2004) and show that fast transport allows firms to smooth demand volatility by reducing the risk of having large quantities of stock during a low demand season. Djankov et al. (2010) point out that timely delivery is also important for selected agricultural products (e.g. fruits and vegetables) due to their low storage life. Moreover, recent studies on the integration of East Asian countries into global value added chains show that delivery time matters especially when just-in-time production processes are applied to minimize storage costs. According to Hummels (2001) and Hummels and Schaur (2012), time-savings appear to be valued highly for product categories in which parts and components are traded (e.g. office equipment, electric power machinery, and photographic equipment).

The time-sensitivity of intermediate inputs for fragmented production chains is shown to have important implications for the location of production and the specialization pattern of countries. This issue is relevant for developing countries in Africa insofar as the gains from intermediate trade are expected to be larger compared to final goods trade (Amiti and Konings 2007, Kasahara and Rodriguez 2008). In

\footnotetext{
See Ando and Kimura (2003) and Athukorala (2005) for a list of parts and components which belong to the machinery and transport equipment sector (SITC 7, HS84-85, HS87-88) and miscellaneous manufactured articles (SITC 8, HS90-92).
} 
this respect, Harrigan and Venables (2006) argue that time costs are qualitatively different from monetary costs (e.g. freight charges) because in a multi-stage production process differences arise due to uncertainties in delivery which can disrupt production. The consequence of this is that delivery time can force producers to order parts and components from nearby sources even if they are more expensive (e.g. due to higher labor cost). That timely delivery influences the choice of sourcing countries is also confirmed by Evans and Harrigan (2005) for final products in the US apparel and textile industry (e.g. fast fashion): import of time-sensitive products from nearby countries (e.g. Mexico) grew much faster than that from East and South Asia. In this respect, Berthelon and Freund (2008), on the one hand, find large scale evidence for the fact that distance became more important in the international delivery of manufacturing products.

On the other hand, Nordas et al. (2006) and Nordas (2007) point out that exporters far from major markets can compensate for their average lead-time in two ways that are not mutually exclusive. Either they can reduce lead-time by shipping their export via air cargo or they can specialize in products with a higher value-to-weight ratio, as airfreight is much more expensive than sea transport. Although air freight costs are on average 5.7 times higher than those of sea freight (Hummels and Schaur 2010 for US imports), the cost of air shipping a kilogram of cargo dropped significantly between 1955 and 2005 (Hummels 2007). The consequence of that is that the value of trade shipped by air grew faster than the weight of trade. In addition, reducing transport costs by increasing competition in air cargo services has recently been under discussion (e.g. Geloso Grosso and Shephard 2011, Sjögren and Söderberg 2011, Kasarda and Green 2005, Micco and Serebrisky 2004) and empirical research points out that more liberal air service policies are positively associated with bilateral trade (especially for timesensitive products) as well as air passenger traffic (Geloso Grosso 2012). Moreover, Harrigan and Deng (2008) and Harrigan (2010) argue that a country is expected to have a comparative advantage in heavy goods in nearby markets and lighter goods in distant markets that can be air-shipped. Thus, for sufficiently high-value products the airfreight premium becomes vanishingly small, making air transport more feasible: Nordas et al. (2006) note that such products exist in most sectors e.g. cut flowers, peas and herbs in the agricultural sector, and brassieres and swimwear in the apparel industry. Their case study shows how trade in air transport services allows Kenya to exploit its comparative advantage in floriculture. While flowers were first transported by passenger flights, dedicated cargo flights became viable as export volume grew. Time cost can affect the choice of transport for certain goods. Shepard et al. (2011) develop an index of 
multimodal transport connectivity which incorporates indicators for air, maritime, and land transport. They estimate a gravity model and find that trade performance is strongly influenced not just by performance in each single mode of transport, but also by the ability to make each transport mode work efficiently and effectively with the others. However, the most frequently applied models determine the modal choice of transport by estimating probit and logit models (McFadden et al. 1985, Jiang et al. 1999). At the product level, Feo-Valero et al. (2003), although they focus on shipping versus road transport (as a faster form of transport), find that high-value sectors (i.e. vehicle parts and household appliances) are significantly affected by logistic services such as transit times and frequency of shipment, while transport costs are more important than transit time for low-value commodities.

When time is an important determinant of the international location of production it is obvious to consider opportunities for time savings. But where do time costs stem from? Firstly, time costs are associated with the net shipping time between the trading countries' ports: Hummels (2001) and Hummels and Schaur (2012) find that, on average, an increase in shipping time of one day reduces the probability that a country will export to the US by 1 per cent (all goods) to 1.5 per cent (manufactures). The market structure of the transport services sector has an important impact on trade flows as it drives much of the variation in shipping prices (Francois and Wooton 2001, Fink et al. 2002, Hummels et al. 2009). In this respect, air cargo carriers can act as potential competitors in disciplining the pricing behavior at shipping liner conferences. Also sea port efficiency affects bilateral trade (Wilson et al. 2003, 2005, Sanchez et al. 2003, Clark et al. 2004, Wilmsmeier et al. 2006, Blonigen and Wilson 2008). Sea port efficiency varies widely from country to country with some of the most inefficient ports located in Africa like Nigeria and Malawi (Clark et al. 2004) making air transport more feasible in that continent. While Wilson et al. (2005) suggests that trade flows grow when an exporter improves its port efficiency, some level of regulation at seaports is beneficial to maintain quality and security conditions (Clark et al. 2004). Ranjan and Lee (2007) find that the trade of differentiated and complex products is more affected by institutional quality. Seaport efficiency also depends on organized crime and corruption which increase transport costs (Anderson and Marcouiller 2002) and create uncertainty about timeliness of delivery so that exporters may prefer air-transport in order to minimize costs and delays (Pomfret and Sourdin 2010). The average South African firm uses about 6 per cent of their overall management time capacity in negotiations with South African government officials (Hallward-Driemeier et al. 2010). 
Sequira and Djankov (2009) suggest that corruption is a major problem at sea ports, e.g. in Durban and Maputo, with bribes that are equivalent to a 14 per cent increase in total shipping cost. In addition, bribes are primarily determined by product characteristics: the probability of a bribe is higher for goods with low elasticity of import demand and increases with storage cost in the port. Therefore, air cargo can be a valid option for firms in Southern Africa where institutional quality is often lower than elsewhere.

Secondly, a significant part of time costs stem from moving goods from the factory to the ship and is often associated with poor infrastructure within a country (Limao and Venables 2001; Elbadawi 2001; Amjadi and Yeats 1995). Shepherd and Wilson (2007) argue that an improvement of road infrastructure, for example in Europe and Central Asia, could increase trade by more than the expected gains from tariff reductions or trade facilitation programs. Moreover, the quality of transport infrastructure like the density of paved road and rail networks, is a main reason for the fact that intra-SubSaharan African (SSA) trade costs are substantially higher (by 136 per cent) than those in non-SSA countries (Limao and Venables 2001) with poor infrastructure accounting for up to 60 per cent of the penalty for landlocked countries. However, De (2006) finds that for selected Asian economies the median landlocked country has transport costs which are 55 per cent higher than for the median coastal economy. Arvis et al. (2010) estimate that landlocked countries in general face a cost penalty ranging widely from 8 to 250 per cent and a time penalty in the range of 9 to 130 per cent compared to their coastal neighbours. On the one hand, Lahiri and Masjidi (2012) argue that landlocked economies should put a high priority on developing their infrastructure and domestic industries to make themselves more attractive as a transit route and a trade partner for coastal economies. On the other hand, diversification of transit options to several neighbours could potentially reduce the monopoly power of any single coastal neighbour in the bargaining process. Given the fact that half of all landlocked countries classified by the UN are located in Africa, air transport seems to be a valuable option for transport to overcome trade barriers not only related to poor transport infrastructure but also to limited access to the ocean.

Thirdly, moving goods from the factory to the ship also involves delays in transport which are due to administrative hurdles, customs and tax procedures, clearances, and cargo inspection within the exporting country (Djankov et al. 2010, Nordas et al. 2006, Hausman et al. 2005). Djankov et al. (2010) show that export times in sub-Saharan Africa are especially long, taking on average more than 40 days. The necessary time to fulfil all the requirements for exporting varies greatly across sub-Saharan Africa. In 
a striking example, they estimate that if Uganda reduces its factory-to-ship time from 58 to 27 days, exports would be expected to increase by 31 per cent. Freytag (2011) compares the trade costs of the South African economy with its African peers and finds that South Africa is in the midrange. ${ }^{2}$ Compared to its competitors, i.e. other emerging nations (e.g. Brazil, China, and Malaysia), South Africa performs poorly (MthembuSalter, 2008).

The business environment in general influences the efficiency with which African firms and industries operate. Moreover, the impact is felt more heavily in sectors heavily involved in trade such as manufacturing and high-value services than in primary production because the former tend to require more intensively inputs of logistics, infrastructure, and regulation (Collier 2000; Eifert et al. 2005). At the firm level, the business environment directly influences costs of production (Eifert et al. 2005; Balchin and Edwards 2008) and evidence suggests strong productivity gains from the trade orientation of the manufacturing sector in African countries (Bigsten et al. 2004; Mengistae and Pattillo 2004; Bigsten and Söderbom 2006). Restrictive trade and customs regulation (Clarke 2005) and the business climate (Balchin and Edwards 2008) deter manufacturing firms in African countries from exporting. Especially firms in timesensitive industries are less likely to become exporters in countries where more time is needed to export as in Africa (Li and Wilson 2009).

Given the low quality of transport infrastructure, high time costs to export and import, and a comparatively higher degree of corruption, we can expect that firms in Southern Africa operating in regional and global markets tend to consider overcoming these trade barriers by relying more on air transport compared to other industrialized countries. Therefore, in this paper we aim to evaluate the prospects for air transport in Southern Africa.

According to the World Bank, in 2012 it required on average 6 documents, 16 days, and 1,620 US dollars per container to export and 7 documents, 23 days, and 1,940 US dollars per container to import (World Bank and International Finance Corporation 2012). 


\section{A Framework for Classifying Air Cargo Products}

\section{A. Methodology}

The transportation costs of a product are mainly determined by the weight of the product and its value. Products can be traded via air, sea, and certain other modes of transport such as road, rail, and inland waterway. Transportation costs vary with the mode of transport. Time and distance to trading partners are relevant determinants for a firm to choose the mode of transport to employ. This means that low value-to-weight products may also be subject to air transport. Those products can be relatively heavy in weight, but time sensitive to production chains. Previous research has solely focused on time sensitivity in delivery to choose products for air cargo (Hummels 2001, Hummels and Schaur 2012, Djankov et al. 2010). Since air freight is much more expensive than sea freight, Nordas et al. (2006) argue that countries can specialize in products with a higher value-to-weight ratio. In doing so, air cargo can be a valid option to overcome barriers to trade in time-sensitive products. For products with a high value to weight ratio, transportation costs and the air premium are explicitly vanishing relative to the value of the product.

Our methodology to classify products relevant for air transport is based on two dimensions to distinguish products into four groups as shown in Figure 1: besides time sensitivity in delivery, the value-to-weight ratio of products is important for air cargo. The value-to-weight ratio serves as a reference value for the air premium and distinguishes products with a high value-to-weight ratio for which air cargo is sufficient (groups L and $\mathrm{H}$ ) and products with a low value-to-weight ratio for which the additional air cost is are comparably high (groups $\mathrm{N}$ and $\mathrm{M}$ ). However, time sensitivity serves as an indicator for delivery time and distinguishes products into a group for which air cargo may become necessary (groups $\mathrm{M}$ and $\mathrm{H}$ ) and products for which delivery time matters less so that air cargo is a rather unlikely choice of transport (groups $\mathrm{N}$ and L). 


\section{Figure 1. Categorizing Air Cargo Products}

\begin{tabular}{|c|c|c|c|}
\hline & \multicolumn{2}{|c|}{ Value-to-weight } \\
\hline & & low & high \\
\hline \multirow{2}{*}{ Time-sensitivity } & low & $\begin{array}{l}\text { Non air cargo relevance } \\
(\text { group } \mathrm{N})\end{array}$ & $\begin{array}{c}\text { Low air cargo relevance } \\
\text { (group L) }\end{array}$ \\
\hline & high & $\begin{array}{c}\text { Medium air cargo relevance } \\
\text { (group } \mathrm{M})\end{array}$ & $\begin{array}{c}\text { High air cargo relevance } \\
\text { (group H) }\end{array}$ \\
\hline
\end{tabular}

In this respect, products belonging to the non-air relevant group $\mathrm{N}$ may consist of bulky products that have a low value-to-weight ratio and low time sensitivity. Products in the low-air relevant group L have a higher value-to-weight ratio but relatively low time sensitivity. The third group with medium air relevance (group M) is the most interesting one as it comprises products with a low value-to-weight ratio but a high time sensitivity. The last group with the highest relevance for air transport (group H) consists of products with high value-to-weight ratio and high time-sensitivity. While for group $\mathrm{H}$ the air premium is acceptable due to a higher value-to-weight ratio, the additional cost of air transport is a relevant determinant for exporters of group $\mathrm{M}$ competing in world markets with products of a lower value-to-weight ratio.

In the absence of data concerning products actually traded within Southern Africa we have to rely on proxies and secondary sources. South Africa's trade data with its main trading partners comprises only value data, not volume data. We develop a statistical implementation using South Africa's trade with the EU as a proxy since equivalent data for South Africa's trade with Africa is not available. South Africa plays an outstanding role in the SADC region, accounting for roughly 40 per cent of intraSADC trade. However, compared to other countries, South Africa is far less integrated with its region. Besides industrialized countries e.g. US and Japan and emerging economies (BRICs), the European Union is the main trading partner of South Africa, absorbing 26 per cent of its total exports in 2010 and, thus, largely determines the total trade structure of South Africa with respect to traded products.

We make use of the rich database provided by the European Statistical Office. The Eurostat database offers access to bilateral trade between the European member states and South Africa on the product level of the Harmonized System HS (Eurostat 2012a) and bilateral trade between the EU and South Africa on the product level by mode of 
transport (Eurostat 2012b). Both datasets include value and volume data. In the Eurostat (2012b) database the sum of all modes of transport add up to the total value traded between South Africa and the European Union. As argued above, the first criterion is value-to-weight ratio. With this ratio we can relate the additional costs of air transport to the products South Africa exports to the EU and the rest of the world. We use data on the EU's imports from South Africa to gain information concerning South Africa's export and production structure. We calculate the value-to-weight ratio and the timesensitivity, i.e., the share of exports transported via air cargo, for each product group at the HS 2-digit-level (Appendix 1). In addition, we calculate the value-to-weight ratio for each product group transported via air and via sea transport. The value-to-weight ratios deviate from year to year due to changes in price ratios. We use the average value-toweight ratio for the period of 2005 to 2010 to smooth out year to year variations and business cycle fluctuations in prices. Based on these two measures, value-to-weight ratio in total trade and time-sensitivity, products are classified into four groups. This classification is then used to evaluate the prospects for air transport in Southern Africa. We make use of the trade data provided by the International Trade Center (ITC) which is completely based on the UNComtrade database. The database reports trade by HS product categories in value (US Dollar) not in volume $(\mathrm{kg})$ for Southern Africa's trade. Before systematically clustering the products relevant for air transport, we consider the loading of an average airplane in the period of 2005 to 2010 bound from South Africa to the EU.

\section{B. Descriptive Statistics}

Consider a number of South African firms exporting their products to the EU. When arriving at an airport, exporters will be charged the transport price of their freight. Depending on the weight and the bulkiness of the export products, the air premium leads to a selection of products for air transport at the check-in desk: for a subgroup of products the air premium is acceptable and, thus, products are made ready for loading. For some products another mode of transport will be chosen when the air premium is too high. Thus, we first analyze the loading of an average airplane by selecting the top 20 products based on their value-to-weight ratio. Second, when an airplane is ready for departure, we make a cargo inspection of the total freight by selecting the top ten products by weight and bulkiness, and thus, products which dominate the cargo freight. 
Most of the top ten products entering the airplane tend to be low value-to-weight products for which time sensitivity matters relatively highly. Finally, with customs clearance at arrival in the EU we combine both the value-to-weight ratio and the time sensitivity of products and systematically classify air cargo relevant goods.

At check-in: we know that the air premium, i.e. the additional cost for shipping by air transport instead of sea transport, becomes smaller with increasing value-to-weight of the product. It tends to be obvious that products with high value-to-weight will be checked-in for air cargo transport. According to Appendix 2, an average airplane bound from South Africa to the European Union has a value-to-weight ratio of 141.76 Euro per $\mathrm{kg}$ which is 342 times higher than the average value-to-weight ratio of the total export basket (0.41 Euro per $\mathrm{kg}$ ). The average value-to-weight ratio of sea cargo transport is comparably low (0.22 Euro per $\mathrm{kg}$ ). This observation holds for all product groups: value-to-weight ratios are higher in an airplane than in a container ship. More interestingly, South Africa exports high value products classified as pearls, jewelry, and coins (HS71) with an outstanding value-to-weight ratio in air transport of nearly 245 Euro per $100 \mathrm{~g}$. Broken down by single goods we find that the product group consists mainly of diamonds (HS7102: 41 \%), gold (HS7108: 34 \%), and platinum (HS7110: 21 $\%$ ). Other products which belong to the high value-to-weight group of goods include aircraft and parts thereof (HS88) as well as optical, photographic, precision instruments (HS90) and clocks and watches and parts thereof (HS91). Each of these top four product groups has a higher value-to-weight ratio than the average airplane cargo that is transported from South Africa to the EU and in sum account for nearly 80 per cent of the air cargo value shipped. However these four product groups make up merely 1.1 per cent of the total loading weight.

The high value-to-weight bundle ready for air transport also includes, according to Appendix 2, not only products of the apparel and clothing industry (HS61,62), silk (HS50), headgear (HS65), leather (HS42) and furskins (HS43), and pharmaceutical products (HS30), but nuclear reactors, boilers and machinery (HS84), ships and boats (HS89), and furniture and lamps (HS94) as well. Even when summing up the top 20 products with the highest value-to-weight ratio listed in the table, roughly three quarters of the average airplane's loading weight remains to be filled, although the product list accounts for nearly 90 per cent of total air cargo value. The last two columns of the table show the time-sensitivity of the products, i.e. the share of total value shipped via air. Accordingly, 37.8 per cent of South Africa's total bilateral export value to the EU is sent via air transport. But with respect to South Africa's export volume in $\mathrm{kg}$, air cargo 
represents not more than 0.1 per cent. Except for a few product groups mentioned above (HS84 and 89 as well as HS30, 61, and 62) more than 50 per cent of each high-value product is shipped by air. The remaining three quarter of the loading weight is filled with products having necessarily a lower value-to-weight ratio, i.e. products of group M. For these product groups the air premium is higher relative to the value of the products and, thus, becomes more important when choosing the mode of transport.

Cargo inspection at departure: when considering the loading of the average airplane from South Africa bound for the EU by weight, a range of agricultural products takes up of the airplane's space (Appendix 3). Fish and crustaceans (HS03), edible vegetables (HS07), and nuts (HS08), live trees and plants (HS06), and meat products (HS02) consume slightly more than 50 per cent of loading weight. However, together they add no more than 1.5 per cent of total air cargo value. Although, it can be expected that nuclear reactors, boilers and machinery (HS84), and furniture and lamps (HS94) will fill out the loading capacity we also find some parts and components of electrical machinery (HS85) and vehicles (HS87) among the cargo. The top ten product groups excluding high value-to-weight products of HS84 and HS94, add another 64 per cent to the air cargo weight but account for slightly less than 10 per cent of its total value.

Summing up, when loading the average airplane with the top 30 products it reaches a capacity of 98.2 per cent of total value, i.e., $89 \%$ due to products in Appendix 2 and 9\% due to products in Appendix 3, and 90.1 per cent of total weight, i.e., 27\% due to products in Appendix 2 and 64\% due to products in Appendix 3. However, most of the airplane's weighting capacity is consumed by lower value-to-weight products which tend to be time-sensitive, i.e. products of group $M$, but some of the airplane's high value-to-weight products for which the air premium becomes vanishingly small (e.g. HS89) tend to have a lower time-sensitivity (e.g. only $2.3 \%$ of products in HS 89 are shipped via air cargo) such that firms are not willing to pay the premium for the products of group L.

Customs clearance at arrival: to classify air cargo relevant goods systematically, it is inevitable to consider time-sensitivity in general but also for the products with high value-to-weight ratios. Table 1 shows that the average value-to-weight of the EU's total imports from South Africa for the period 2005 to 2010 is 41.4 Euro per $100 \mathrm{~kg}$, the average value-to-weight of the EU's total imports via air transport is 14,176 Euro per $100 \mathrm{~kg}$ due to an outlier as argued above (HS71 with a unit-value of 413,970 Euro per $100 \mathrm{~kg}$ ). As HS71 is an important product group in South Africa's trade we cannot exclude it from the calculation. Thus, to distinguish between high and low value-to- 
weight products, not excluding the HS71 outlier, the median value-to-weight ratio (which is 423 Euro per 100kg) in EU imports from South Africa is appropriate rather than the average value-to-weight ratio. Accordingly, 50 product groups are above the median and belong to the high value-to-weight group (groups $\mathrm{L}$ and $\mathrm{H}$ in Figure 1) and 50 product groups are below the median (groups $\mathrm{N}$ and $\mathrm{M}$ ).

Table 1. Customs Clearance at Arrival

(Time-Sensitivity and Value-to-Weight Ratios)

\begin{tabular}{|c|c|c|c|c|c|c|c|c|c|}
\hline \multirow{3}{*}{$\begin{array}{c}\text { Products } \\
\text { Total }\end{array}$} & \multicolumn{3}{|c|}{ Value-to-weight } & \multicolumn{6}{|c|}{ Time-sensitivity } \\
\hline & \multicolumn{3}{|c|}{$\begin{array}{c}\text { Total Air cargo Sea cargo } \\
\text { (Euro } / 100 \mathrm{~kg})\end{array}$} & \multicolumn{3}{|c|}{$\begin{array}{l}20052010 \text { Average } \\
\text { (air cargo value / total) }\end{array}$} & \multicolumn{3}{|c|}{$\begin{array}{l}20052010 \quad \text { Average } \\
\text { (air cargo volume / total) }\end{array}$} \\
\hline & 41 & 14176 & 22 & 27.7 & 44.4 & 37.8 & 0.1 & 0.2 & 0.1 \\
\hline $\begin{array}{l}\text { Non air relevant } \\
(\mathrm{N})\end{array}$ & 17 & 459 & 15 & 0.6 & 1.2 & 0.9 & 0.0 & 0.1 & 0.0 \\
\hline $\begin{array}{l}\text { Low air relevant } \\
\text { (L) }\end{array}$ & 762 & 1466 & 717 & 3.1 & 1.6 & 2.5 & 1.1 & 1.2 & 1.3 \\
\hline $\begin{array}{c}\text { Medium air relevant } \\
\text { (M) }\end{array}$ & 23 & 3344 & 15 & 9.4 & 29.6 & 31.4 & 0.2 & 0.2 & 0.2 \\
\hline $\begin{array}{l}\text { High air relevant } \\
(\mathrm{H})\end{array}$ & 5970 & 33430 & 1287 & 61.5 & 81.6 & 73.6 & 10.2 & 18.8 & 13.2 \\
\hline
\end{tabular}

(Note) See Appendixes 1 and 4 for detailed information on product categories.

(Source) Calculation based on Eurostat (2012a,b). 


\section{Figure 2. Classification of Products}

(Time Sensitivity and Value to Weight Ratios)

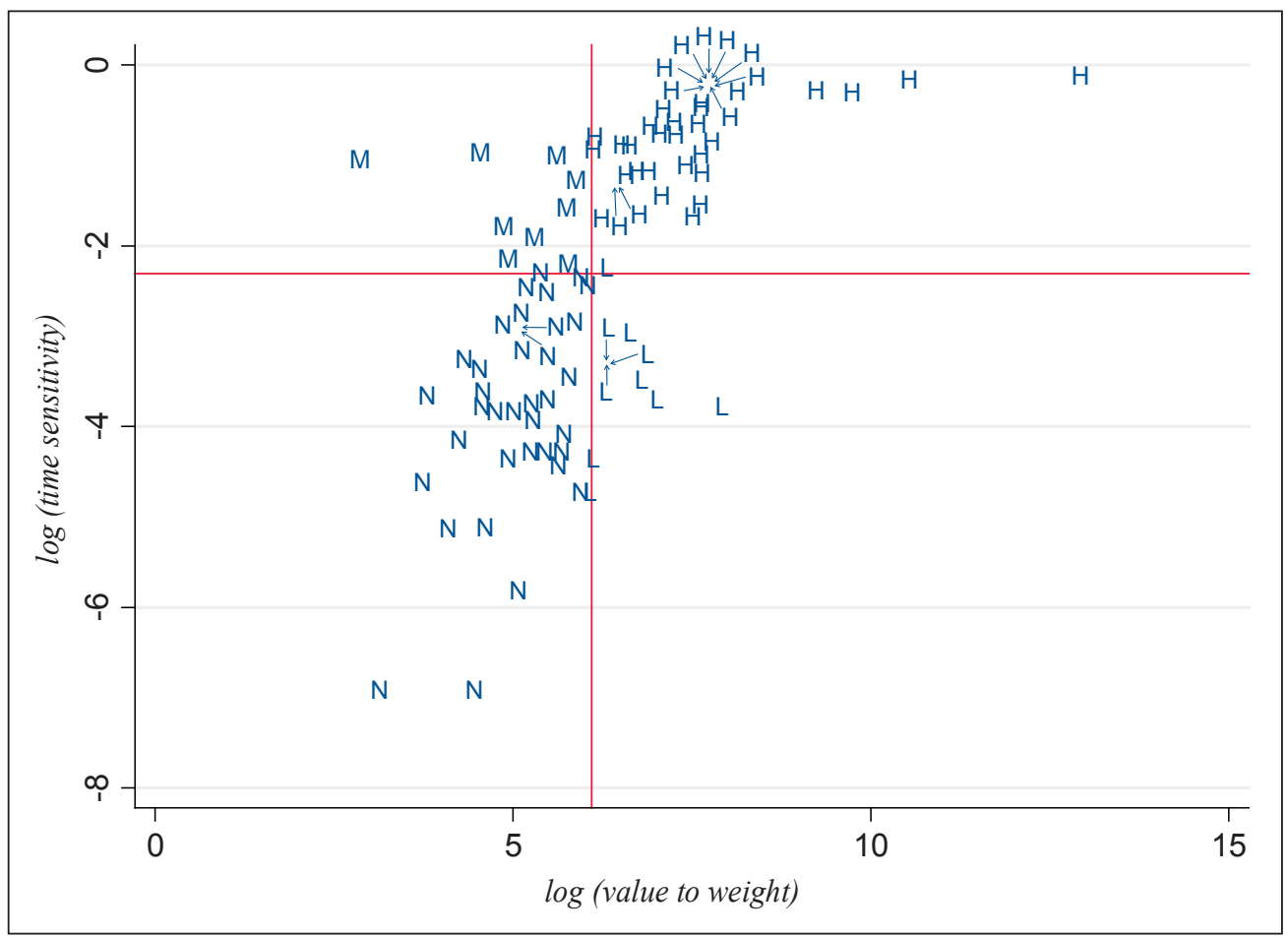

(Note) H: High air cargo relevance, M: Medium air cargo relevance, L: Low air cargo relevance, N: Non air cargo relevance

(Source) own compilation based on Eurostat (2012a,b).

With respect to the time-sensitivity of products, table 1 shows that, on average, 37.8 per cent of the total export value from South Africa to the EU is transported via air cargo. Air cargo becomes even more important: the share of air freight out of all transport modes has increased from 27.7 per cent in 2005 to 45 per cent in 2010 . However, merely 0.1 per cent of total export volume is sent by air. We cluster products into groups with high time-sensitivity and low time-sensitivity using the median of air cargo transport value compared to total transport value, which is 10.7 per cent. The median splits the product groups for which more than 10.7 per cent of total export value is shipped by air (groups $\mathrm{M}$ and $\mathrm{H}$ in Figure 1) and products with lower air transport probability (groups $\mathrm{N}$ and L).

Figure 2 visualizes how products are clustered into the four groups ranging from non-air relevant products $(\mathrm{N})$ in the lower left quarter to high air relevant group $(\mathrm{H})$ in 
the upper right quarter. The solid lines represent the median of each of the two cluster dimensions: time-sensitivity and value-to-weight ratio. While products in group $\mathrm{H}$ have a high value-to-weight ratio and high time-sensitivity, products in groups $\mathrm{M}$ and $\mathrm{L}$ have either a high time-sensitivity (group $\mathrm{M}$ ) or a high value-to-weight ratio (L). Group N products have neither a high value-to-weight ratio nor high time-sensitivity. Products in the high air relevant group $\mathrm{H}$ have the highest probability of being air shipped because of both their high value-to-weight ratios (on average 59.70 Euro per kg according to table 1) but also with respect to their time-sensitivity (on average $74 \%$ of the export value is shipped by air). ${ }^{3}$

Interesting to note are products belonging to the medium air relevance group $\mathrm{M}$. Although air shipped, those products have a relatively low unit value (on average 0.23 Euro per $\mathrm{kg}$ ) but these products have a higher time-sensitivity (on average $31.4 \%$ of the total value is shipped via air transport). These product groups include some agricultural products, e.g. fish and crustaceans (HS03), edible vegetables (HS07) (e.g. potatoes, tomatoes, onions, garlic, lettuce, chicory, carrots, turnips, cucumber, and frozen and dried vegetables) ${ }^{4}$, and sugar and confectionary (HS17). However, also ores, slag, and ash (HS26) which contain a range of rare earth (e.g. manganes, copper, nickel, cobalt, aluminum, lead, zinc, tin, chromium, tungsten, uranium, titanium, and other rare earths) are included as well as some inorganic chemicals and products thereof (HS28, 38), raw hides and leather (41), cotton (52), and articles of stone, plaster, and cement (HS68).

In contrast, the other two categories of products with non- and low air relevance contain products for which delivery time is not as important, so other modes of transport are favorable. Products in the group with low air relevance (L) have on average a higher value-to-weight ratio (7.62 Euro per $\mathrm{kg}$ ) than products in the medium air relevance group ( 0.23 Euro per $\mathrm{kg}$ ), but the time-sensitivity is comparatively low $(2.5 \%$ of the value is shipped by air) such that air transport is feasible with respect to the air premium but not necessary for reasons of time constraints. Accordingly, products in this group include rather time-insensitive agricultural products (e.g. dairy products, honey (HS04),

\footnotetext{
3 According to the classification, group $\mathrm{H}$ consists of products with a high relevance for air cargo, e.g. some agricultural products such as live animals (HS01), meat (HS02), products of animal origin (HS05), live trees and other plants (HS06), and some time-sensitive products from the apparel and clothing industry categories (HS60-65) but also leather and furskins (HS42, 43), silk (HS50), and textile fabrics that are woven (HS58) or impregnated (HS59). The product list contains also a range of parts and components from the electrical machinery section (HS82-85), aircraft (HS88), optical parts (HS90), clocks and watches (HS91), musical instruments (HS92), and pearls, stones, and coins (HS71). We also find pharmaceutical products (HS30), printed books and newspapers (HS49), and ceramic products (HS69) among these products.

${ }^{4}$ Interesting to note, edible fruits and nuts (HS08) have a relatively low probability of being exported by air ( 3 per cent of export is shipped by air) and show up in the non-relevant air product list. Edible vegetables (HS07) emerging in the list with medium air cargo relevance tend to be more time-sensitive ( 38 per cent of export is transported via air cargo).
} 
vegetable extracts (HS13), cocoa and preparations (HS18), textile fabrics (wool and animal hair (HS51) and carpets (HS57)), raw materials like nickel and copper (HS74, 75), vehicles (HS87), and ships and boats (HS89).

Products in the non-air relevant group are also time-insensitive (on average $0.9 \%$ are subject to air transport) but have by far the lowest value-to-weight ratio (on average 0.17 Euro per kg). Accordingly, group N consists of mineral fuels (HS27) and products thereof plastic (HS39), other raw materials ${ }^{5}$, and all other preparations of agricultural and bulky products.

\section{Random Classifications derived from Cluster Analysis}

An alternative classification scheme can be derived from a cluster analysis which attempts to determine natural groupings of observations. Partition-clustering is a method to partition $n$ observations into $k$ non-overlapping clusters. This would be appropriate to reproduce our type of clustering since each product is assigned to only one of the four groups instead of a being part of a hierarchical ordering of products. Moreover, the clustering of products occurs randomly so that each observation belongs to the cluster with the nearest mean in order to minimize the within-cluster sum of squares. The distance measure most commonly used for continuous data is the Euclidean distance $d_{i j}=\left[\sum_{a=1}^{p}\left(x_{i a}-x_{j a}\right)^{2}\right]^{1 / 2}$ where $p$ represent the number of variables (i.e. value-toweight ratio and time-sensitivity) and $x_{i a}$ and $x_{j a}$ denote, respectively, the value of the $a$-th variable for product groups $i$ and $j$. This distance measure $d_{i j}$ can be interpreted as the physical distance between two $p$-dimensional points in Euclidean space (Everitt et al. 2011, 49p). Since our dataset is highly skewed with respect to the two dimensions of value-to-weight ratio and time-sensitivity - due to outliers in the product space (i.e. products in HS71) - we use the log of the observation values. As starting centers for the $k$ groups, $k$ unique observations are chosen at random, from among those to be clustered around the nearest mean. The cluster algorithm is iterated one million times.

\footnotetext{
${ }^{5}$ Metal products (e.g. iron, steel, and articles thereof (HS72, 73), aluminum (HS76), lead (HS78), zinc (79), and other base metals (81)), as well as wood, cork, and products thereof (HS44, 47, 48), and glasses (HS70).

${ }^{6}$ Edible fruits (HS08), cereals (HS10, 19), meat and fish (HS16), vegetables (HS20, 21), coffee, tea, mat, and spices (HS09), milling products (HS11), and oil seeds and grains (HS12). The list also contains beverages and tobacco (HS22-24), organic chemicals (HS29), fertilizers (HS31), tanning or dying extracts (HS32), soap (HS34), and rubber (HS40).
} 
Table 2. Comparison of Classification Schemes

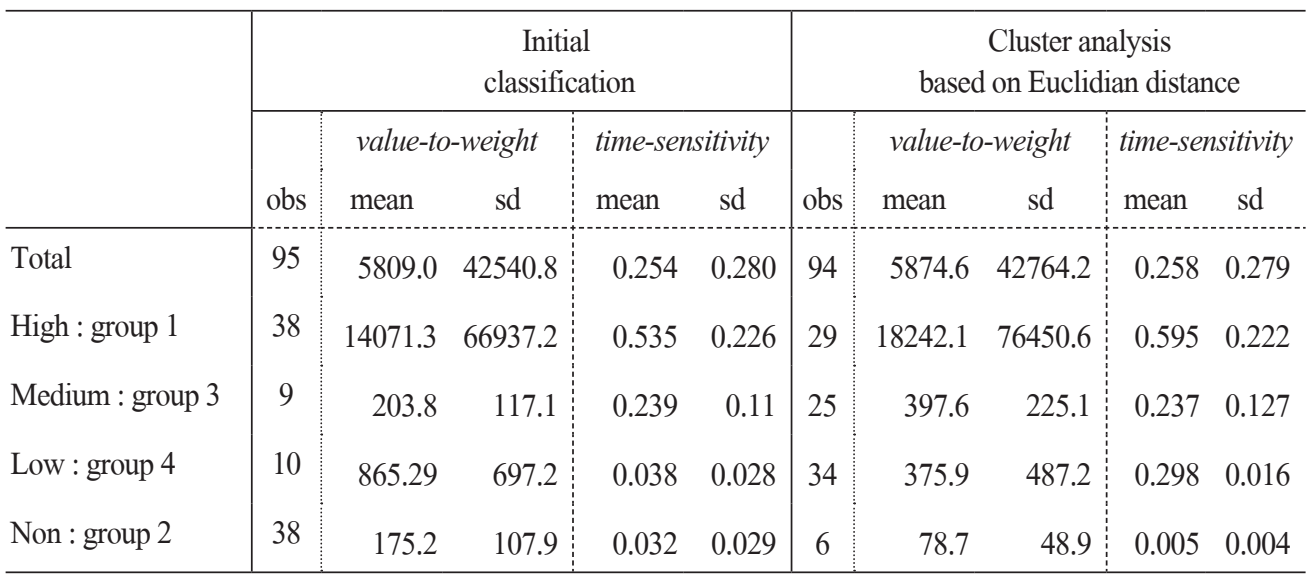

(Note) See Appendixes 1 and 4 for detailed information on product categories.

(Source) Calculation based on Eurostat (2012a,b).

\section{Figure 3: Classification of Products based on Euclidian Distance}

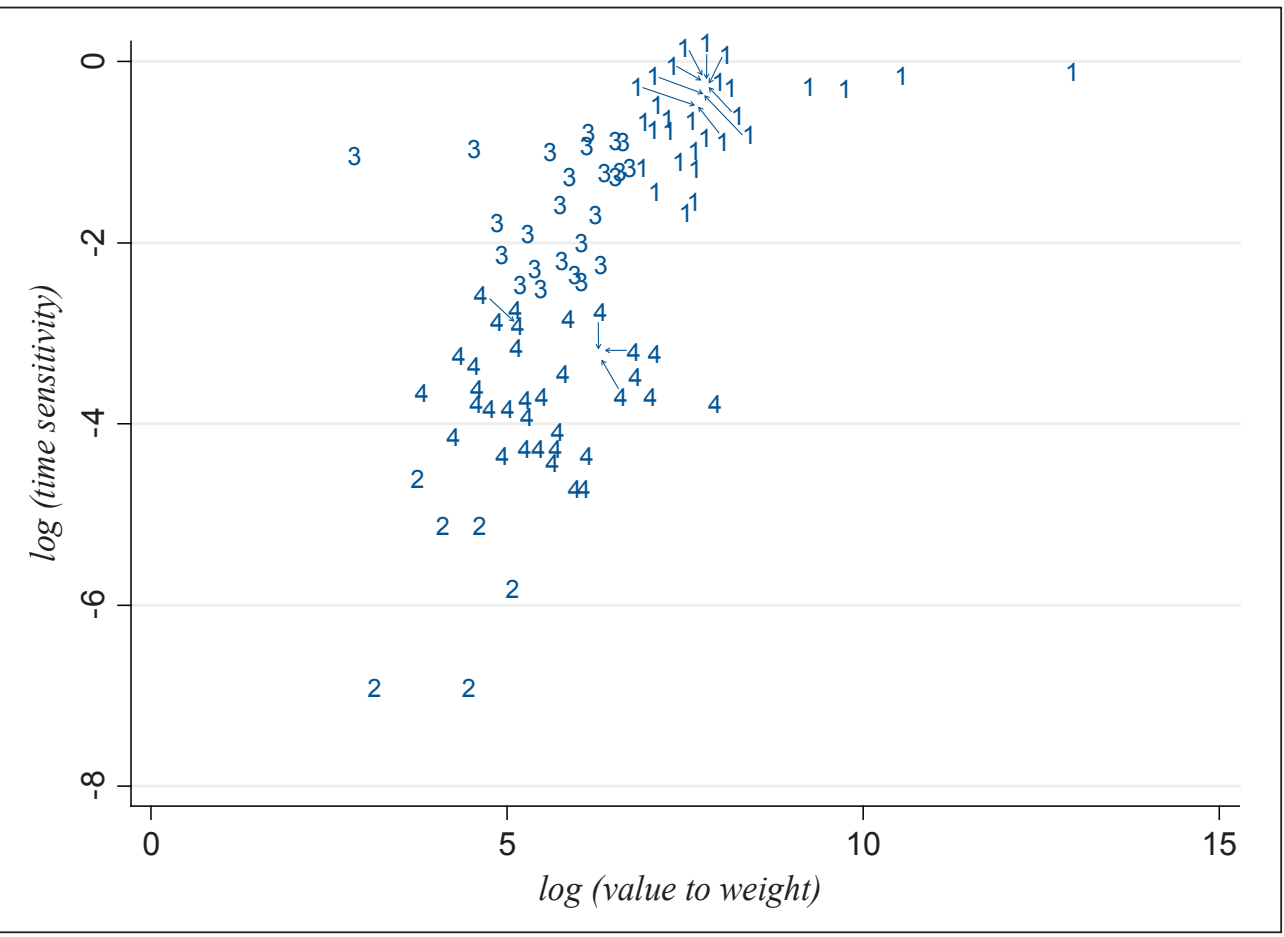

(Source) own compilation based on Eurostat (2012a,b). 
Figure 3 shows the resulting clustering of products into $k=4$ random groups. The clusters derived from cluster analysis are somewhat similar to our systematic classification in Figure 2 with the high air relevant group in the upper right quarter and the non-air relevant group in the lower left quarter. However, the two groups in the middle part of Figure 3 tend to differ only with respect to time-sensitivity. Table 2 includes descriptive statistics from both classifications. For the random classification based on cluster analysis, the means of the value-to-weight ratios of both groups in the middle part, groups 3 and 4, are in the same range. Also the group means of time-sensitivity variable vary only slightly from 0.237 in group 3 to 0.298 in group 4 (compared to 0.595 in group 1 and 0.005 in group 2) and suggest that both group 3 and 4 can be pooled. Although the random clustering builds upon the distance to the nearest mean to minimize the within-cluster sum of squares, the standard deviation for the value-to-weight ratio in both group 1 and 3 is even higher in the random clustering than in the systematic classification developed in this paper. Moreover, in our classification, both groups $\mathrm{M}$ and $\mathrm{L}$ differ significantly with respect to both variables according to Table 2, with products having higher value-to-weight ratios and low time-sensitivity (group L) and vice versa (group M).

The classification for air cargo products developed in this paper is a systematic distinction of products. The HS nomenclature of trade statistics on which the classification is based accounts for the products' degree of processing which is reflected in the two dimensions - value-to-weight ratio and time-sensitivity. The advantage of this categorization lies in the allocation of the "fresh" part of a product (e.g. fish and meat within [HS01, 02, and 03]) - which is more time sensitive - to the high and medium air relevant group (depending on value-to-weight ratio) and the "dried and prepared" part of a product (e.g. meat and fish within [HS16]) to the non- or low air cargo relevant group - in which delivery time is less important because the quality of the product will not deteriorate with shipment. With increasing degree of processing some products lose their sensitivity to delivery time (e.g. canned instead of fresh fish) so that the air premium can be avoided, while other products receive higher value-toweight ratios (e.g. textile fabrics [HS 61, 62, and 64] instead of cotton [HS52]) so that the air premium becomes acceptable. 


\section{Limitations}

When using this classification scheme to analyze South Africa's exports to countries other than the European Union members we need to be aware of several limitations. The classification is a rough approximation of product groups shipped between South Africa and the European Union. For clustering of products into groups we derive two criteria at the product level and not at the country level and the value and weight of HS product categories is used. The only assumption that is made is that the same products in the HS categories are exported from South Africa to all trading partners but in different quantities not qualities.

South Africa is the largest exporter and importer in the SADC region. As argued in the previous section, several factors affect a firm's decision to choose a certain mode of transport. Those factors include geographical characteristics e.g. the distance to the trading partner: a greater distance makes air transport more viable. This implies rather a lower probability of air transport for intra-African trade, which occurs at rather shorter distances. On the other hand, the poor transport infrastructure available i.e. the poor quality of paved roads and rail increases the probability to choose air freight. In addition, for the nearly half of countries within the SADC which are landlocked (Zambia, Zimbabwe, Botswana, Lesotho, and Swaziland) sea transported products may be shipped by air. In addition, border barriers and customs procedures may hinder transport to ports. Firms may decide to choose air freight to limit the remaining transport time. Also in the presence of corruption, which is a severe problem in most of the countries in Southern Africa, exporters prefer air transport in order to minimize costs and delays within the exporting country. Especially for institution-sensitive goods, corruption creates uncertainty about timeliness of delivery (Levchenko 2007; Pomfret and Sourdin 2010). These reasons rather strengthen our hypothesis that air transport tends to be a valuable option in Southern Africa.

\section{Prospects for Air Cargo in Southern Africa}

\section{A. South Africa's Trade with Industrialized Economies and BRICs}

The framework established above is used to evaluate the development of air 
transport in Southern Africa. We first concentrate on South Africa's total trade with the world and make a comparison to South Africa's exports to the European Union and other main industrialized countries. The EU is by far the largest trading partner of South Africa. Together with the US and Japan, nearly 46 per cent of South Africa's exports are directed to this group of industrialized countries. The second largest group of trading partners includes the BRICs countries with China (11.4\%), India (4.2\%), and Brazil (1\%) receiving almost 17 per cent of South Africa's products. The SADC countries account for roughly 13 per cent of South Africa's exports with the main trading partners being Zimbabwe (3\%), Mozambique (2.6\%), and Zambia (2.4\%).

South Africa's total trade pattern by air cargo relevance is shown in Table 3 . The non-air relevant group, which includes a range of bulky products, is by far the largest group of South Africa's export bundle, in sum 41 per cent in $2010 .^{7}$ Although South Africa's total exports have grown by 52 per cent in value over the last five years, the share of these bulky products grew at a much lower rate so that its relevance has declined slightly. Although South Africa exports a much higher share of bulky products in the non-air relevant group to other SADC members (53\% of exports in 2010) their importance has tended to diminish since 2005 as well. South Africa's total export bundle contains 30 per cent of products with a high relevance for air transport (group $\mathrm{H}$ ) and an additional 18 per cent of products with medium air relevance (group M). These product groups have seen considerable export growth in the last five years. Especially the medium air relevant products with a relatively low value-to-weight ratio have become to a greater extent subject to air transport due to their time-sensitivity. Exports of these medium air relevant products (especially ores, slag, and ashes (HS26) alone account for $14 \%$ in 2010 ) grew by $141 \%$ over the last five years. They do, however, not show up to a noticeable extent in South Africa's exports to SADC members, while the export of high air relevant products to SADC members is at the same level compared to South Africa's total trade pattern.

In the group of time-sensitive products with high value-to-weight ratios (group $\mathrm{H}$ ), the main product group is HS71 (pearls, precious stones, and metals, including diamonds, gold, and platinum), which accounts for nearly 17 per cent of South Africa's total export value. As shown for an average airplane from South Africa to the EU, these products make up an indiscernible percentage of the total cargo volume and capacity. When excluding HS71 from South Africa's total export bundle, the share of high air

\footnotetext{
South Africa's exports are made up of the following main categories: 10\% mineral fuels (HS27), $13 \%$ iron, steel, and articles thereof (HS72, 73), and 3\% aluminium (HS76) in 2010.
} 
relevant products in total exports drops from 30 per cent to merely half that number $(16 \%$ in 2010). This is obviously not the case for exports to other SADC members in which the respective export figures remain at their initial level. Certainly, HS71 accounts for less than 0.1 per cent of South Africa's exports to the SADC.

Table 3. South Africa's Trade Clustered by the Air Cargo Relevance of Product Groups

\begin{tabular}{|c|c|c|c|c|c|c|c|c|c|c|}
\hline & \multicolumn{5}{|c|}{ South Africa - World } & \multicolumn{5}{|c|}{$\begin{array}{c}\text { South Africa - Southern African } \\
\text { Development Community (SADC) }\end{array}$} \\
\hline & \multirow[b]{2}{*}{2005} & \multirow[b]{2}{*}{2010} & \multirow{2}{*}{$\begin{array}{l}\text { Growth } \\
2005 \sim 10\end{array}$} & \multicolumn{2}{|c|}{ Excl. HS71 } & \multirow[b]{2}{*}{2005} & \multirow[b]{2}{*}{2010} & \multirow{2}{*}{$\begin{array}{l}\text { Growth } \\
2005 \sim 10\end{array}$} & \multicolumn{2}{|c|}{ Excl. HS71 } \\
\hline & & & & 2005 & 2010 & & & & 2005 & 2010 \\
\hline & \multicolumn{10}{|c|}{ Exports } \\
\hline $\begin{array}{l}\text { Total } \\
\text { of which (\%): }\end{array}$ & 46,988 & 71,447 & 52.1 & - & - & 5,013 & 8,947 & 78.5 & - & - \\
\hline Non-air & 44.3 & 41.3 & 41.6 & 54.2 & 49.4 & 58.5 & 53.0 & 61.9 & 58.5 & 53.1 \\
\hline Low-air & 10.7 & 11.4 & 62.4 & 13.1 & 13.7 & 7.4 & 8.9 & 113.1 & 7.4 & 8.9 \\
\hline Medium-air & 11.1 & 17.6 & 140.9 & 13.5 & 21.0 & 6.0 & 6.2 & 85.0 & 6.0 & 6.2 \\
\hline \multirow[t]{2}{*}{ High-air } & 33.9 & 29.7 & 33.4 & 19.2 & 15.9 & 28.1 & 31.8 & 102.5 & 28.0 & 31.8 \\
\hline & \multicolumn{10}{|c|}{ Imports } \\
\hline $\begin{array}{l}\text { Total } \\
\text { of which (\%): }\end{array}$ & 50,234 & 74,898 & 49.1 & - & - & 1,596 & 3,753 & 135.2 & - & - \\
\hline Non-air & 33.5 & 40.3 & 79.2 & 34.3 & 40.7 & 29.6 & 72.4 & 477.0 & 41.6 & 80.1 \\
\hline Low-air & 12.3 & 10.6 & 28.0 & 12.6 & 10.7 & 11.0 & 6.1 & 29.6 & 15.5 & 6.7 \\
\hline Medium-air & 5.1 & 4.4 & 28.2 & 5.2 & 4.4 & 23.4 & 3.2 & -67.6 & 33.0 & 3.6 \\
\hline High-air & 49.0 & 44.7 & 36.0 & 47.9 & 44.1 & 36.0 & 18.2 & 18.9 & 9.9 & 9.7 \\
\hline
\end{tabular}

(Note) Total trade figures in millions of USD excluding exports and imports of HS 99, other commodities n.e.s. South Africa exports of HS71 amount to 18.2 per cent (2005) and 16.5 per cent (2010). The import of HS71 makes up 2.2 per cent (2005) and 1.1 per cent (2010) of total imports. In trade of HS71 with the SADC, South Africa exports less than 0.1 per cent, but imports by between 29 per cent (2005) and 9.5 per cent (2010). See Appendixes 1 and 4 for detailed information on product categories.

(Source) Calculation based on ITC (2012).

Considering South Africa's imports from the rest of the world compared to imports from SADC members it becomes obvious that South Africa tends to be the hub of the region, delivering pearls and precious stones from the SADC to the rest of the world, while redirecting machinery and electrical equipment from the rest of the world to 
its SADC partners. South Africa's import of goods with the highest probability of air cargo (group H) accounts for 45 per cent of its imports. Mainly machinery, electrical equipment, and parts thereof (HS84, 85) are imported by South Africa (27\% of total imports) from the rest of the world, while South Africa's high air relevant imports from the SADC is rather made up of pearls, gold, and platinum. HS71 alone accounts for 29 per cent of imports from the SADC in 2005, but shrinks to a level of 10 per cent in 2010. Excluding these HS71 products from the import bundle, the importance of air transportable products from SADC members to South Africa dwindles to a level of 10 per cent and remains far below the trade flows in the opposite direction (32\% of South Africa's exports to the SADC in 2010) which consist mainly of machinery, electrical equipment, and parts thereof (HS84, 85 account for $21 \%$ in 2010).

South Africa's trade by air transport probability with the rest of the world is shown in more detail in Appendixes 5 and 6. In Appendix 5 we find that South Africa's trade with industrialized countries, especially with the EU, contains a much larger share of products with a considerable extent of air relevance (35\% of exports belong to the group with the highest air cargo probability). Exports of medium air relevant products to the EU (14.2\% of exports) have grown even faster (by 48\% since 2005) than South Africa's total exports to the EU (10\% since 2005). On the other hand, products in the non-air relevant group have decreased from $43.5 \%$ in 2005 to $38 \%$ in 2010 . A similar picture emerges for South Africa's imports: more than 50 per cent of products South Africa imports from the EU belong to the group with high air relevance. In South Africa's trade with other industrialized countries (i.e. the US and Japan) air transportable products are even more important than in trade with the EU. ${ }^{8}$ In general, the export and import of products with a high relevance for air cargo transport are considerably above the level in South Africa's total trade.

The air cargo relevance in South Africa's trade with industrialized countries is in contrast to trade with BRIC countries (Appendix 6), mainly due to the fact that South Africa specializes in trade of resource-intensive products. However, when differentiating resource-intensive products by time-sensitivity and value-to-weight ratio we find that only in trade relations with Brazil and India do resource-intensive exports belonging to the non-air relevant group dominate. More than 70 per cent of South Africa's exports to

\footnotetext{
${ }^{8}$ In 2010, 38\% of South Africa's exports to the US consist of products with a high relevance for air transport, although export of these products has grown at a below average rate (of total trade which is $44.3 \%$ since 2005 ) of $15 \%$, the importance of air transportable products in trade with the US has dropped remarkably since 2005. The contrary is the case for South Africa's export of high air relevant products to Japan, which has increased from a level of $37 \%$ in 2005 to $53 \%$ in 2010.
} 
both countries are made up of products that have a very low probability to be transported via air cargo. ${ }^{9}$ However, the picture changes dramatically when considering South Africa's trade relations with China: two thirds of exports to China belong to the medium air relevant group. Not surprisingly, the most important products delivered to China are ores, slag, and ashes (HS26, which includes the complete range of rare earths). These product groups alone account for 54 per cent of total exports to China.

Compared to South Africa's exports to industrialized countries, the importance of products with a high relevance for air transport in trade relations with BRICs countries is far below the average level of South Africa's exports. Nevertheless, the relevance for air cargo transport remains for South Africa's imports from BRICs. Especially imports from China contain an outstanding proportion of products with high air relevance $(75 \%$ in 2010): mainly machinery, electrical equipment, and parts thereof (HS84, 85) which contribute $44 \%$ of South Africa's imports from China. A remaining $15 \%$ of imports from China include fabrics of the apparel and clothing industry as well as footwear (HS59 64). However, South Africa's imports from Brazil contain a rather larger share (18 per cent) of meat and preparations thereof $(\mathrm{HS} 02,05)$ in addition to machinery and electrical equipment which account for $20 \%$ of imports from Brazil. India is rather a provider of pharmaceutical products (HS30) which account for $8 \%$ of imports which rank second behind the import of machinery and electrical equipment (13\%).

\section{B. South Africa's Air Cargo Trade with SADC Partners}

Relative to South Africa's exports to industrialized countries, which consist in large part of air transportable goods (especially diamonds, gold, and platinum in HS71), and its exports to emerging BRICs countries, which consist of bulky resourceintensive products, South Africa's trade with SADC members with respect to air transportable goods lies somewhere in between. Table 4 summarizes the export and import figures with South Africa's main SADC trading partners: Zambia, Zimbabwe, and Mozambique, which absorb 2.4\%, 3\%, and 2.6\% of South Africa's exports, respectively. Although South Africa's exports to all three countries include a relatively

\footnotetext{
${ }^{9}$ While $60 \%$ of total exports to India are mineral fuels (HS27), the export bundle to Brazil is rather a broad mix of $16 \%$ mineral fuels, $17 \%$ iron and steel (HS72), and 10\% aluminum (HS76) as well as 12\% chemicals (HS29). The relatively large share of export of air transportable goods to India in 2005 is due to an outlier: aircraft and parts thereof (HS88) accounted for $20 \%$ of total exports to India in this year.
} 
large share of bulky non-air transportable products (around 50 per cent) ${ }^{10}$, time-sensitive products with a high value-to-weight ratio relevant for air cargo transport (group $\mathrm{H}$ ) become even more important. The largest share of these high air relevant products is directed from South Africa to Zambia (which account for 38\% of total exports to Zambia). In trade with Zimbabwe and Mozambique, the share of air transportable products is slightly lower, i.e. 30 per cent of South Africa's total exports to each of these countries. It is noteworthy that mainly machinery, electrical equipment, and parts thereof (HS84, 85) play a dominant role, accounting for more than $28 \%$ of South Africa's exports to Zambia, and comparatively lower levels in trade with Zimbabwe and Mozambique (18\% and 22\%, respectively).

Table 4. South Africa's Trade with Zambia, Zimbabwe, and Mozambique

\begin{tabular}{|c|c|c|c|c|c|c|c|c|c|}
\hline & \multicolumn{3}{|c|}{ South Africa - Zambia } & \multicolumn{3}{|c|}{ South Africa - Zimbabwe } & \multicolumn{3}{|c|}{ South Africa - Mozambique } \\
\hline & 2005 & 2010 & $\begin{array}{c}\text { Growth } \\
2005 \sim 10\end{array}$ & 2005 & 2010 & $\begin{array}{c}\text { Growth } \\
2005 \sim 10\end{array}$ & 2005 & 2010 & $\begin{array}{c}\text { Growth } \\
2005 \sim 10\end{array}$ \\
\hline & \multicolumn{9}{|c|}{ Exports } \\
\hline $\begin{array}{l}\text { Total } \\
\text { of which (\%): }\end{array}$ & 849 & 1,750 & 106.1 & 1,162 & 2,155 & 85.6 & 992 & 1,893 & 90.9 \\
\hline Non-air & 47.6 & 45.8 & 98.5 & 65.0 & 56.7 & 62.0 & 68.0 & 53.3 & 49.6 \\
\hline Low-air & 9.8 & 10.7 & 125.2 & 6.6 & 9.0 & 151.3 & 6.7 & 9.6 & 176.6 \\
\hline Medium-air & 7.8 & 5.0 & 33.7 & 6.2 & 5.6 & 68.1 & 3.6 & 6.9 & 263.4 \\
\hline \multirow[t]{2}{*}{ High-air } & 34.8 & 38.4 & 127.2 & 22.2 & 28.7 & 139.6 & 21.7 & 30.1 & 165.1 \\
\hline & \multicolumn{9}{|c|}{ Imports } \\
\hline $\begin{array}{l}\text { Total } \\
\text { of which (\%): }\end{array}$ & 204 & 289 & 41.5 & 488 & 191 & -60.8 & 30 & 528 & 1639.6 \\
\hline Non-air & 7.5 & 6.9 & 30.4 & 20.6 & 52.6 & 0.0 & 45.6 & 94.8 & 3511.2 \\
\hline Low-air & 43.9 & 58.6 & 88.9 & 16.7 & 13.8 & -67.7 & 3.7 & 0.4 & 81.4 \\
\hline Medium-air & 39.4 & 11.7 & -58.1 & 54.8 & 22.4 & -84.0 & 36.3 & 2.4 & 15.2 \\
\hline High-air & 9.2 & 22.8 & 250.2 & 7.8 & 11.2 & -44.0 & 14.4 & 2.5 & 195.9 \\
\hline
\end{tabular}

(Note) Total trade figures in millions of USD excluding exports and imports of other commodities n.e.s. (HS99). See Appendixes 1 and 4 for detailed information on product categories.

(Source) Calculation based on ITC (2012).

\footnotetext{
${ }^{10}$ It is noteworthy that, while South Africa's exports to Mozambique in this product group is largely dominated by mineral fuels (HS27) with $17 \%$, the export bundle to Zambia and Zimbabwe is even more diversified, including at least $10 \%$ fuels and several other products like plastics (HS39), fertilizers (HS31), iron, steel, and articles thereof (HS72 ,73), as well as animal and vegetable fats and oils (HS15).
} 
In contrast to South Africa's trade with industrialized countries, export of products such as diamonds, gold, and platinum included in HS71 turn out to be relatively unimportant in South Africa's exports to SADC members. This observation holds also for South Africa's imports from Zambia, Zimbabwe, and Mozambique of which HS71 accounts for less than 0.4 per cent. ${ }^{11}$ In this respect, it is even more remarkable that South Africa's exports of the remaining air cargo relevant products to other SADC members grew at above average relative to total exports rates in the last five years. Especially exports of air cargo relevant products to Mozambique increased by 165 per cent in this period, which is far beyond the growth rate of total trade $(91 \%)$. Comparable numbers can be observed for exports to Zambia (127\% compared to $106 \%$ ) and to Zimbabwe (140\% compared to $86 \%$ ). However, South Africa's imports from the selected SADC partners differ substantially, with air cargo relevant products at a comparatively low level (i.e. $11.2 \%$ of imports from Zimbabwe and $2.5 \%$ of imports from Mozambique), except for trade relations with Zambia for which HS71 suddenly emerged with $6.8 \%$ in the import statistics in 2010 .

Given the fact that export of diamonds, gold, platinum, and all other pearls and precious stones included in HS71 leave the loading space and volume of an average airplane largely unaffected, they account for less than 1 per cent of the total volume shipped, it is reasonable to correct South Africa's trade flows by the "invisible outliers" in the air cargo freight. Results are reported in Table 5.

${ }^{11}$ Except for an outlier in trade with Zimbabwe in 2010, HS71 accounts for 7\% of total imports. 


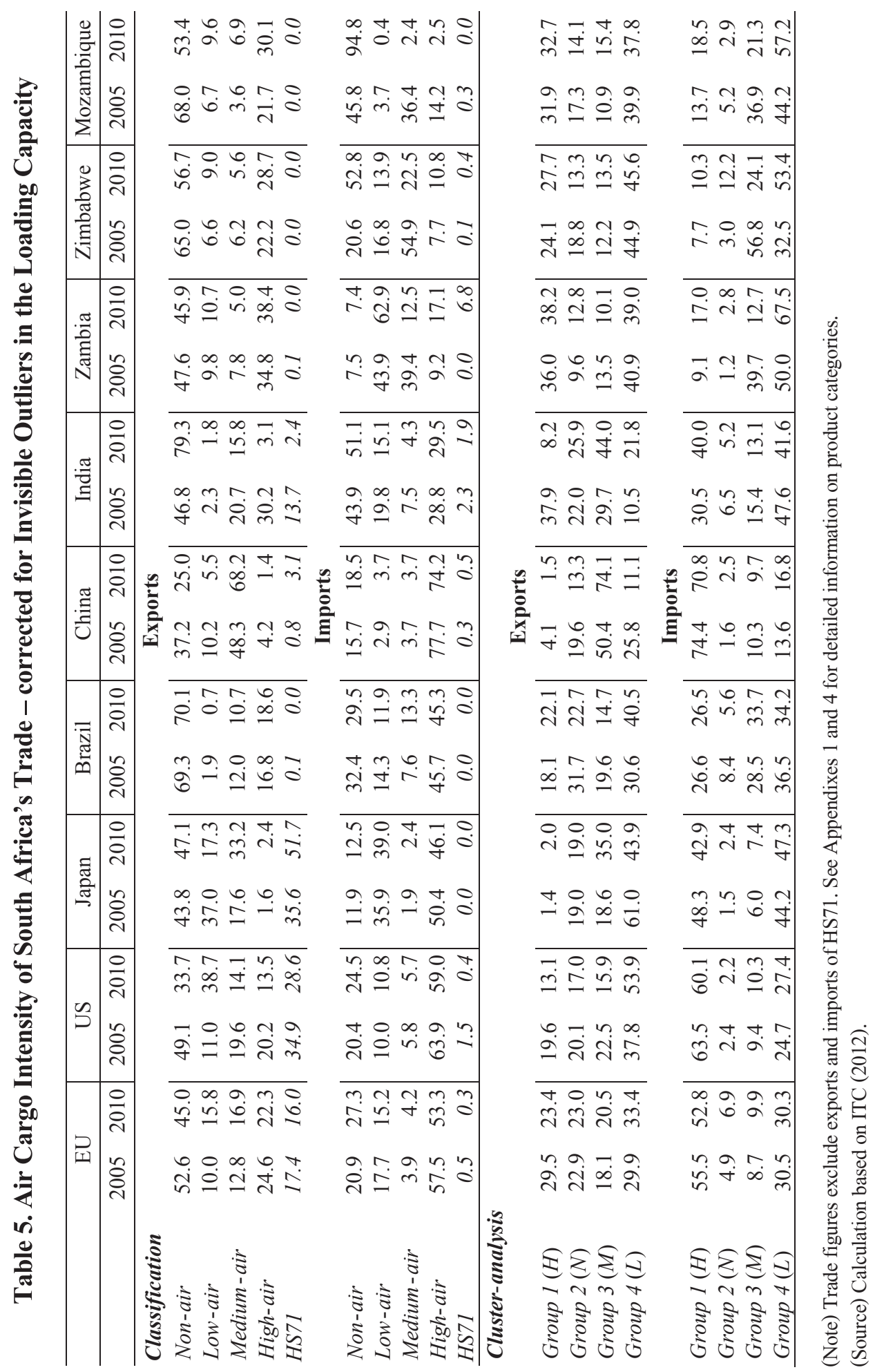


The relevance of the remaining time-sensitive products with high value-to-weight ratios in trade with SADC members is even more remarkable. Notably, South Africa's export bundle to selected SADC members includes more products subject to a high probability of air cargo than in exports to selected industrialized countries. Except for exports to the European Union, for which high air cargo relevant products account for $22.3 \%$ in 2010 , and thus were slightly above the respective level in South Africa's export bundle to the rest of the world (compare Table 2), air cargo relevant exports account for not more than $14 \%$ of exports to the US and even less than $3 \%$ in trade with Japan. According to Table 5, the results do not change when applying the classification derived from cluster analysis. South Africa exports a higher share of products belonging to the high air relevant group 1 to SADC members in its neighborhood than to industrialized countries and BRICs.

\section{Prospects for intra-SADC Air Cargo Transport}

South Africa tends to export a larger share of products with high air relevance to their neighboring SADC partners than to industrialized countries and emerging BRIC countries when correcting trade flows by invisible outliers in the average airplane's loading capacity. Although South Africa is the largest trading country in SADC and, thus, dominates overall intra-SADC trade flows to a high extent, it is crucial to check whether South Africa's air cargo relevant trade deviates from trade among its SADC partners. Thus, the trade pattern of SADC members by air transportable product groups is shown in more detail in Table 6. Here we compare intra-SADC trade, i.e. the bilateral trade between all SADC members, with the SADC members' exports and imports to and from non-SADC members and with the SADC's world trade. Both intra- and extraSADC trade add up to the SADC's total world trade.

Although intra-SADC trade accounts for roughly a fifth of the SADC's total trade (13\% of exports and $20 \%$ of imports are delivered within the SADC), it is noteworthy that intra-SADC total exports and imports have grown at much higher rates in the last five years than SADC's trade with non-SADC members. While intra-SADC exports grew by 105 per cent from 2005 to 2010 we find a growth rate of somewhat below 80 per cent for exports to non-SADC members. Even more remarkable is that the growth of intra-SADC trade occurred especially in those product groups we have classified as relevant for air cargo transport (i.e. the medium and high air probability products). In 
more detail, compared to the growth of intra-SADC's exports (105\% as argued above), exports of products belonging to the group with high air relevance grew at a similar rate, but medium air relevant products increased by 171 per cent in that period. The growth rates for both medium and high air relevant products outperformed the corresponding growth rates for SADC's exports to non-SADC members, which increased by 135 per cent (medium air group) and 16 per cent (high air group).

Table 6. SADC Trade clustered by the Air Cargo Relevance of Product Groups

\begin{tabular}{|c|c|c|c|c|c|c|c|c|c|}
\hline & \multicolumn{3}{|c|}{ Intra-SADC } & \multicolumn{3}{|c|}{ SADC - world } & \multicolumn{3}{|c|}{ Extra-SADC } \\
\hline & 2005 & 2010 & $\begin{array}{c}\text { Growth } \\
2005 \sim 10\end{array}$ & 2005 & 2010 & $\begin{array}{c}\text { Growth } \\
2005 \sim 10\end{array}$ & 2005 & 2010 & $\begin{array}{c}\text { Growth } \\
2005 \sim 10\end{array}$ \\
\hline & \multicolumn{9}{|c|}{ Exports } \\
\hline $\begin{array}{l}\text { Total } \\
\text { of which (\%): }\end{array}$ & 10,234 & 20,945 & 104.7 & 89,565 & 163,221 & 82.2 & 79,331 & 142,275 & 79.3 \\
\hline Non & 46.0 & 43.9 & 95.2 & 53.0 & 55.9 & 92.2 & 53.9 & 57.6 & 91.8 \\
\hline Low & 11.3 & 10.4 & 89.8 & 7.9 & 11.1 & 158.4 & 7.4 & 11.3 & 171.9 \\
\hline Medium & 10.8 & 14.3 & 170.9 & 9.3 & 12.3 & 140.1 & 9.2 & 12.0 & 135.4 \\
\hline \multirow[t]{2}{*}{ High } & 31.9 & 31.4 & 101.2 & 29.8 & 20.7 & 26.4 & 29.6 & 19.1 & 16.0 \\
\hline & \multicolumn{9}{|c|}{ Imports } \\
\hline $\begin{array}{l}\text { Total } \\
\text { of which (\%): }\end{array}$ & 14,743 & 28,034 & 90.2 & 83,341 & 141,990 & 70.4 & 68,597 & 113,956 & 66.1 \\
\hline Non & 46.9 & 49.0 & 98.4 & 36.4 & 41.2 & 92.9 & 34.1 & 39.3 & 91.3 \\
\hline Low & 14.4 & 12.5 & 64.4 & 14.2 & 12.1 & 45.1 & 14.1 & 12.0 & 40.8 \\
\hline Medium & 9.2 & 10.7 & 122.1 & 5.6 & 5.9 & 79.7 & 4.8 & 4.7 & 62.3 \\
\hline High & 29.5 & 27.8 & 79.7 & 43.8 & 40.9 & 58.8 & 46.9 & 44.1 & 56.0 \\
\hline
\end{tabular}

(Note) Total trade figures in millions of USD excluding exports and imports of other commodities n.e.s. (HS 99). Half of intra-SADC exports and SADC exports to the world originate from South Africa. The difference between intra-SADC exports and imports tends to be due to an underreporting of exported products perhaps for reasons of tax avoidance. See Appendixes 1 and 4 for detailed information on product categories.

(Source) Calculation based on ITC (2012). 
Table 7. Air Cargo Intensity of SADC Trade - corrected for Invisible Outliers

\begin{tabular}{lcccc|cccc|cccc}
\hline & \multicolumn{3}{c|}{ Intra-SADC } & \multicolumn{3}{c|}{ SADC - World } & \multicolumn{5}{c}{ Extra-SADC } \\
\hline & \multicolumn{2}{c}{ Exports } & \multicolumn{2}{c|}{ Imports } & \multicolumn{2}{c|}{ Exports } & Imports & \multicolumn{2}{c}{ Exports } & \multicolumn{2}{c}{ Imports } \\
& 2005 & 2010 & 2005 & 2010 & 2005 & 2010 & 2005 & 2010 & 2005 & 2010 & 2005 & 2010 \\
\hline Classification & & & & & & & & & & & & \\
Non-air & 48.8 & 46.0 & 48.5 & 50.1 & 63.6 & 63.2 & 36.9 & 41.9 & 65.9 & 65.9 & 34.5 & 39.9 \\
Low-air & 11.9 & 10.9 & 14.9 & 12.8 & 9.4 & 12.6 & 14.4 & 12.3 & 9.1 & 12.9 & 14.3 & 12.2 \\
Medium-air & 11.4 & 15.0 & 9.5 & 11.0 & 11.2 & 13.9 & 5.7 & 6.0 & 11.2 & 13.7 & 4.9 & 4.8 \\
High-air & 27.9 & 28.1 & 27.0 & 26.1 & 15.7 & 10.3 & 43.0 & 39.8 & 13.9 & 7.5 & 46.3 & 43.1 \\
HS71 & 5.6 & 4.6 & 3.3 & 2.4 & 16.8 & 11.6 & 1.5 & 1.8 & 18.2 & 12.6 & 1.1 & 1.7 \\
Cluster Analysis & & & & & & & & & & & & \\
Group 1 (H) & 28.5 & 29.8 & 26.1 & 28.9 & 22.1 & 16.3 & 45.8 & 44.3 & 20.8 & 12.9 & 50.2 & 47.9 \\
Group 2 $(N)$ & 12.8 & 11.6 & 11.6 & 11.8 & 17.9 & 14.4 & 6.0 & 7.1 & 18.9 & 15.0 & 4.8 & 6.0 \\
Group 3 $(M)$ & 20.1 & 24.3 & 18.8 & 19.1 & 22.1 & 27.9 & 12.9 & 13.1 & 22.5 & 28.8 & 11.7 & 11.7 \\
Group 4 $(L)$ & 38.7 & 34.1 & 43.1 & 40.4 & 38.0 & 41.4 & 35.1 & 35.5 & 37.7 & 43.3 & 33.3 & 34.3 \\
\hline
\end{tabular}

(Note) Trade figures exclude exports and imports of diamonds, gold, and platinum (HS71). See Appendixes 1 and 4 for detailed information on product categories

(Source) Calculation based on ITC (2012).

When correcting SADC import and export flows by invisible outliers (i.e. diamonds, gold, platinum, and all other pearls and precious stones included in HS71), we find that in intra-SADC trade the importance of the high air relevant product group remains at a level of 27 per cent, while for SADC members' exports to the rest of the world (extraSADC), the share of high air relevant products dropped to half the level of intra-SADC trade, i.e. from $30 \%$ to $14 \%$ in 2005 and from $19 \%$ to $8 \%$ in 2010 , when excluding the 'invisible outliers'. According to Table 7, the results do not change when the classification from cluster analysis is applied. The share of group 1 products is higher in intra-SADC trade. Diamonds, gold, platinum, pearls, and other precious stones (HS71) are even less relevant for intra-SADC trade than in trade with the rest of the world. 


\section{Conclusions}

In this paper we evaluate the prospects for air cargo transport in Southern Africa. South Africa has become even more incorporated in global value chains with timesensitive products being increasingly exported. Given the low quality of transport infrastructure, high time costs to export and import, and a comparatively higher degree of corruption, we argue that firms in Southern Africa operating in foreign markets may consider overcoming these trade barriers by relying more on air cargo compared to other industrialized countries.

We developed a framework to systematically classify air cargo relevant products. The classification builds upon two important criteria: the time-sensitivity and the valueto-weight ratio of products. The argument behind this classification scheme is that the air premium, i.e. the additional cost of shipping via air instead of sea, becomes vanishingly small for products with a high value-to-weight ratio (e.g. diamonds, gold, and platinum) irrespective of time sensitivity. However, also products with a relatively low value-to-weight ratio (e.g. fruits and vegetables) can be subject to air cargo mainly due to low storage life and, thus, time-sensitivity. For these products the air premium becomes an even more important determinant when choosing the mode of transport.

Since detailed data about intra-African air transport are lacking, we make use of a large database provided by the European Union which is by far the largest trading partner of South Africa and, in this respect, covers to a large extent the trade and production structure with respect to the product level. We first evaluate the freight of an average airplane to derive average value-to-weight ratios and time-sensitivity measures at the product level according to which products are then systematically classified. The classification is, secondly, used to analyze prospects for air transport in Southern Africa.

We find that especially the export of products with high and medium air cargo relevance grew much faster in the last five years than exports of bulky goods and nonair cargo relevant products. South Africa's export bundle includes diamonds, gold, and platinum (HS71), which account for 17 per cent of total export value and rises to one third in trade with industrialized countries, especially the US and Japan. These products, however, leave the loading weight of an average airplane almost unaffected (less than one per cent of the five year average air cargo volume of flights to the EU). It seems that these 'invisible outliers' are so precious that they tend to be transported in the hand baggage of business or security personnel since its loading accounts for 
more than three quarters of the value of an average airplane. When correcting South Africa's trade for these invisible outliers we find that South Africa exports a much larger share of products with high air cargo relevance to its SADC partners (i.e. Zambia, Zimbabwe, and Mozambique) than to industrialized countries (i.e. EU, US, and Japan). These results indicate that air transport is a valuable option to overcome trade barriers associated with infrastructure and corruption. In this respect, reducing transport cost by increasing competition in air cargo services will allow the continent to integrate even further.

Received 14 May 2013, Revised 27 August 2013, Accepted 30 August 2013

\section{References}

Aizenman, J. (2004), Endogenous pricing to market and financing costs, Journal of Monetary Economics, Vol. $51(4), 691-712$

Amiti, M. and J. Konings (2007), Trade liberalization, intermediate inputs and productivity: evidence from Indonesia, The American Economic Review, Vol. 97(5), 1611-1638.

Amjadi, A. and A.J. Yeats (1995), Have transport costs contributed to the relative decline of sub-Saharan African exports?: some preliminary empirical evidence, World Bank Policy Research Working Paper No. 1559, The World Bank.

Amjadi, A., U. Reinke, and A.J. Yeats (1996), Did external barriers cause the marginalization of sub-Saharan Africa in world trade? World Bank Policy Research Working Paper No. 1586, The World Bank.

Anderson, J.E., and D. Marcouiller (2002), Insecurity and the pattern of trade: an empirical investigation, Review of Economics and Statistics, Vol. 84, 342-52.

Ando, M. and F. Kimura (2003), The formation of international production and distribution networks in East Asia, NBER Working Paper No. 10167, National Bureau of Economic Research.

Arvis, J.F., G. Raballand, and J.F. Marteau (2010), The cost of being landlocked: Logistics costs and supply chain reliability, Directions in development: Trade, The World Bank, Washington, D.C.

Athukorala, P. (2005), Product fragmentation and trade patterns in East Asia, Asian Economic Papers, Vol. 4(3), 1-27.

Balchin, N. and L. Edwards (2008), Trade related business climate and manufacturing export performance in Africa: A firm-level analysis, Journal of Development Perspectives, Vol. 1(4), 67-92.

Berthelon, M. and C. Freund (2008), On the conservation of distance in international trade, Journal of International Economics, Vol. 75(2), 310-320.

Bigsten, A., P. Collier, S. Dercon, M. Fafchamps, B. Gauthier, J.W. Gunning, A. Oduro, R. Oostendorp, C. Pattillo, M. Söderbom, F. Teal, and A. Zeufack (2004), Do African manufacturing firms learn from exporting?, Journal of Development Studies, Vol. 4(3), 115-141. 
Bigsten, A. and M. Söderbom (2006), What have we learned from a decade of manufacturing enterprise surveys in Africa? The World Bank Research Observer, Vol. 21(2), 241-265.

Blonigen, B.A., and W.W. Wilson (2008), Port efficiency and trade flows, Review of International Economics, Vol. 16(1), 21-36.

Clark, X., D. Dollar, and A. Micco (2004), Port efficiency, maritime transport costs, and bilateral trade, Journal of Development Economics, Vol. 75(2), 417-450.

Clarke, G. (2005) Beyond Tariffs and Quotas: Why Don't African Manufacturers Export More? World Bank Policy Research Working Paper No. 3617. The World Bank.

Collier, P. (2000), Africa's comparative advantage, in H. Jalilian, M.A. Tribe, and J. Weiss (eds.): Industrial development and policy in Africa: issues of de-industrialisation and development strategy, Cheltenham: Elgar, 11-21.

De, P. (2006), Trade, infrastructure and transaction costs: The imperatives for Asian economic cooperation, Journal of Economic Integration, 21(4), 708-735.

Djankov, S., C. Freund, and C.S. Pham (2010), Trading on time, The Review of Economics and Statistics, Vol. 92(1), 166-173.

Eifert, B., Gelb, A. and Ramachandran, V. (2005) Business Environment and Comparative Advantage in Africa: Evidence from the Investment Climate Data, Center for Global Development Working Paper No. 56, February 2005.

Elbadawi, I.A. (2001), Can Africa export manufactures? The role of endowment, exchange rates, and transaction costs, In Augustin Nsouli, Kwasi Fosu, and Aristomene Varoudakis (eds): Policies to Promote Competitiveness in Manufacturing in Sub-Saharan Africa. Paris: OECD.

Eurostat (2012a), Comext Database, EU27 Trade since 1988 by HS2-HS4, available at: http://epp.eurostat. ec.europa.eu/newxtweb/, last retrieval: November 2012.

Eurostat (2012b), Comext Database, EU27 Trade since 2000 by Mode of Transport (HS2-HS4), available at: http://epp.eurostat.ec.europa.eu/newxtweb/, last retrieval: November 2012.

Evans, C.L. and J. Harrigan (2005), Distance, time and specialization: lean retailing in general equilibrium, The American Economic Review, Vol. 95(1), 292-313.

Everitt, B.S., S. Landau, M. Leese, and D. Stahl (2011), Cluster analysis, 5th edition, Wiley: Hoboken, N.J.

Feo-Valero, M., L. Garcia-Menendez, I. Martinez-Zarzoso, and E.M. Perez-Garcia (2003), Determinants of modal choice for freight transport: Consequences for the development of short-sea shipping between Spain and Europe, Instituto de Economía International, Universidad de Valencia, Spain, mimeo.

Fink, C., A. Mattoo, I.C. Neagu (2002), Trade in international maritime services: how much does policy matter, The World Bank Economic Review, Vol. 16(1), 81-108.

Francois, J.F. and I. Wooton (2001), Trade in international transport services: the role of competition, Review of International Economics, Vol. 9(2), 249-261.

Freytag, A. (2011), Cumulative cost of trade protection in the South African economy, SAIIA, Occasional Paper 80, Johannesburg.

Geloso Grosso, M. (2012), Air passenger transport in the APEC: Regulatory impacts and prospects for Asia Pacific Integration, Journal of Economic Integration, Vol. 27(2), 312-327. 
Geloso Grosso, M., and B. Shephard (2011), Air cargo transport in APEC: regulation and effects on merchandise trade, Journal of Asian economics, Vol. 22(3), 203-212.

Hallward-Driemeier, M., G. Khun-Jush, and L. Pritchett (2010), Deals versus rules: policy implementation uncertainty and why firms hate it, World Bank Policy Research Working Paper No. 5321, The World Bank.

Harrigan, J. (2010), Airplanes and comparative advantage, Journal of International Economics, Vol. 82(2), 181-194.

Harrigan, J. and H. Deng (2008), China's local comparative advantage, NBER Working Paper No. 13963, National Bureau of Economic Research.

Harrigan, J. and A. Venables (2006), Timeliness and agglomeration, Journal of Urban Economics, Vol. 59(2), $300-316$

Hausman, W.H., L. Lee and U. Subramanian (2005), Global logistics indicators, supply chain metrics and bilateral trade patterns, World Bank Policy Research Working Paper No. 3773, The World Bank.

Hummels, D.L. (2001), Time as a trade barrier, GTAP Working Paper No. 17, Centre for Global Trade Analysis.

Hummels, D.L. (2007), Transportation costs and international trade in the second era of globalization, The Journal of Economic Perspectives, Vol. 21(3), 131-154.

Hummels, D.L., and G. Schaur (2012), Time as a trade barrier, NBER Working Paper No. 17758, National Bureau of Economic Research.

Hummels, D.L., and G. Schaur (2010), Hedging price volatility using fast transport, Journal of International Economics, Vol. 82(2), 15-25.

Hummels, D., V. Lugovskyy and A. Skiba (2009), The trade reducing effects of market power in international shipping, Journal of Development Economics, Vol. 89(1), 84-97.

ITC (2012), Trademap, International Trade Centre, available at: http://www.trademap.org/, last retrieval: November 2012.

Jiang, F., P. Johnson, and C. Calzada (1999), Freight demand characteristics and mode choice: An analysis of the results of modeling with disaggregated revealed preference data, Journal of Transportation and Statistics, Vol. 2(2), 149-158.

Kasahara, H. And J. Rodrigue (2008), Does the use of imported intermediates increase productivity? Plant-level evidence, Journal of Development Economics, Vol. 87(1), 106-118.

Kasarda, J.D. and J.D. Green (2005), Air cargo as an economic development engine: A note on opportunities and constraints, Journal of Air Transport Management, Vol. 11(6), 459-462.

Lahiri, B. and F. K. Masjidi (2012), Landlocked countries: A way to integrate with coastal economies, Journal of Economic Integration, Vol. 27(4), 505-519.

Levchenko, A. (2007), Institutional quality and international trade, Review of Economic Studies, Vol. 74(3), 791-819.

Li, Y. and J.S. Wilson (2009), Time as a determinant of comparative advantage, World Bank Policy Research Working Paper No. 5128, The World Bank.

Limao, N., and A.J. Venables (2001), Infrastructure, geographical disadvantage, transport costs, and trade, The World Bank Economic Review, vol. 15(3), 451-479. 
McFadden, D., C. Winston, and A. Boersch-Supan (1985), Joint estimation of freight transportation decisions under nonrandom sampling, in A.F. Daughety (ed.): Analytical Studies in Transport Economics, Cambridge University Press: Cambridge.

Mengistae, T. and C. Pattillo (2004), Export orientation and productivity in Sub-Saharan Africa, IMF Staff Papers, Vol. 51(2), $327-353$

Micco, A. and T. Serebrisky (2004), Infrastructure, competition regimes, and air transport costs: Cross-country evidence, World Bank Policy Research Working Paper No. 3355. The World Bank.

Mthembu-Salter, G. (2008), The costs of non-tariff barriers to business along the North-South Corridor (South Africa-Zimbabwe) via Beit Bridge, Johannesburg: SAIIA Trade Policy Report No 20.

Ng, F. and Yeats, A. (1996), Open economies work better: Did Africa's protectionist policies cause its marginalisation in world trade? World Bank Policy Research Working paper No. 1636. The World Bank: Washington DC.

Nordas, H.K. (2007), Time as a trade barrier: Implications for low-income countries, OECD Economic Studies, Vol. 2006/1, OECD: Paris.

Nordas, H.K., E. Pinali, and M. Geloso Grosso (2006), Logistics and time as a trade barrier, OECD trade policy working paper No. 35, OECD:Paris.

Pomfret, R. and P. Sourdin (2010), Why do trade costs vary?, Review of World Economics, Vol. 146(4), 709730.

Ranjan, P. and J.Y. Lee (2007), Contract enforcement and international trade, Economics and Politics, Vol. 19(2), 191-218.

Rodrik, D. (1997), Trade policy and economic performance in Sub-Saharan Africa, National Bureau of Economic Research Working paper no. 6562. Cambridge, M.A.

Sanchez, R.J., J. Hoffmann, A. Micco, G. Pizzoletto, M. Sgut, and G. Wilmsmeier (2003), Port efficiency and international trade: Port efficiency as a determinant of maritime transport, Maritime Economics and Logistics, Vol. 5, 199-218.

Sequiera, S. and S. Djankov (2009), On the Waterfront: An Empirical Study of Corruption in Ports, http:// siteresources.worldbank.org/DEC/Resources/84797-1257266550602/SequeiraS.pdf, retrieved: November 2012.

Shepherd, B., and J. Wilson (2007), Road infrastructure in Europe and Central Asia: Does network quality affect trade?, Journal of Economic Integration, Vol. 22(4), 723-747.

Shepherd, B., R.B. Serafica, A. Bayhaqi and H. Jing (2011), The trade impact of enhanced multimodal connectivity in the Asia-Pacific Region, Journal of Economic Integration, Vol. 26(4), 624-650.

Sjögren, S. and M. Söderberg (2011), Productivity of airline carriers and ist relation to deregulation, privatisation and membership in strategic alliances, Transportation Research, Vol. 47(2), 228-237.

Wilmsmeier, G., J. Hoffmann, R. Sanchez (2006), The impact of port characteristics on international maritime transport costs, in: Cullinane, K., and W.K. Talley (Eds.), Port Economics, Research in Transportation Economics, vol.16. Elsevier.

Wilson, J.S., C. Mann, and T. Otsuki, (2005), Assessing the Benefits of Trade Facilitation: A Global Perspective, The World Economy, Vol. 28(6), 841-871.

Wilson, J.S., C. Mann, and T. Otsuki (2003), Trade facilitation and economic development: A new approach to 
quantifying the impact, The World Bank Economic Review, Vol. 17(3), 367-389.

Wood, A. and J. Mayer (2001), Africa's export structure in a comparative perspective, Cambridge Journal of Economics, Vol. 25(3), 369-394.

World Bank and International Finance Corporation (2012), Doing Business 2013, The World Bank: Washington DC. 


\section{Appendices}

Appendix 1:

South Africa's Exports to the EU by Product Group and Air Cargo Relevance

\begin{tabular}{|c|c|c|c|c|c|c|c|c|c|c|}
\hline \multicolumn{2}{|c|}{ Classification } & \multicolumn{4}{|c|}{ Air cargo exports, South Africa to EU } & \multicolumn{3}{|c|}{ Value-to-weight (Euro/100kg) } & \multirow{2}{*}{\multicolumn{2}{|c|}{$\begin{array}{c}\text { Time-sensitivity } \\
\text { Air cargo total }\end{array}$}} \\
\hline & & & & & & & & & & \\
\hline HS & Air & $100 \mathrm{~kg}$ & $\%$ & 1000 Euro & $\%$ & Total & Air & Sea & Value & Volume \\
\hline Total & & 547299 & 100.00 & 7721791.0 & 100 & 41.4 & 14175.7 & 21.8 & 37.8 & 0.1 \\
\hline 01 & $\mathrm{H}$ & 148 & 0.03 & 440.6 & 0.01 & 2525.4 & 3000.5 & 2128.9 & 78.6 & 67.8 \\
\hline 02 & $\mathrm{H}$ & 8407 & 1.54 & 8517.6 & 0.11 & 832.9 & 1014.5 & 752.3 & 31.4 & 25.8 \\
\hline 03 & M & 144916 & 26.48 & 58978.5 & 0.76 & 356.6 & 403.5 & 339.2 & 28.2 & 24.9 \\
\hline 04 & $\mathrm{~L}$ & 2 & 0.00 & 2.9 & 0.00 & 563.9 & 1499.6 & 510.6 & 3.7 & 12.9 \\
\hline 05 & $\mathrm{H}$ & 621 & 0.11 & 1407.2 & 0.02 & 1211.6 & 2412.8 & 650.1 & 62.5 & 34.0 \\
\hline 06 & $\mathrm{H}$ & 33048 & 6.04 & 17687.3 & 0.23 & 467.3 & 551.6 & 383.1 & 45.8 & 39.7 \\
\hline 07 & $\mathrm{M}$ & 16739 & 3.06 & 6481.2 & 0.08 & 93.7 & 387.4 & 59.1 & 38.3 & 9.6 \\
\hline 08 & $\mathrm{~N}$ & 94612 & 17.29 & 30273.0 & 0.39 & 98.0 & 322.7 & 90.5 & 2.7 & 0.8 \\
\hline 09 & $\mathrm{~N}$ & 313 & 0.06 & 236.5 & 0.00 & 196.6 & 1017.6 & 190.6 & 2.0 & 0.5 \\
\hline 10 & $\mathrm{~N}$ & 144 & 0.03 & 27.1 & 0.00 & 75.3 & 775.4 & 69.4 & 3.9 & 0.7 \\
\hline 11 & $\mathrm{~N}$ & 14 & 0.00 & 4.0 & 0.00 & 41.9 & 314.1 & 40.3 & 1.0 & 0.1 \\
\hline 12 & $\mathrm{~N}$ & 515 & 0.09 & 1449.5 & 0.02 & 173.1 & 2564.0 & 167.5 & 5.9 & 0.4 \\
\hline 13 & $\mathrm{~L}$ & 76 & 0.01 & 141.7 & 0.00 & 555.3 & 1872.8 & 507.1 & 10.7 & 3.3 \\
\hline 14 & $\mathrm{~N}$ & 19 & 0.00 & 13.2 & 0.00 & 93.8 & 3577.9 & 91.6 & 3.5 & 0.3 \\
\hline 15 & $\mathrm{~N}$ & 65 & 0.01 & 43.1 & 0.00 & 280.1 & 921.8 & 290.7 & 1.2 & 0.6 \\
\hline 16 & $\mathrm{~N}$ & 230 & 0.04 & 128.5 & 0.00 & 383.0 & 596.8 & 381.7 & 0.9 & 0.7 \\
\hline 17 & M & 232 & 0.04 & 241.2 & 0.00 & 128.8 & 944.3 & 96.5 & 17.0 & 3.0 \\
\hline 18 & $\mathrm{~L}$ & 74 & 0.01 & 82.7 & 0.00 & 764.1 & 1139.1 & 752.2 & 5.2 & 4.0 \\
\hline 19 & $\mathrm{~N}$ & 21 & 0.00 & 13.9 & 0.00 & 138.7 & 708.0 & 136.9 & 1.3 & 0.3 \\
\hline 20 & $\mathrm{~N}$ & 1416 & 0.26 & 563.6 & 0.01 & 100.3 & 376.0 & 102.5 & 0.6 & 0.1 \\
\hline 21 & $\mathrm{~N}$ & 1478 & 0.27 & 1107.6 & 0.01 & 239.9 & 918.2 & 216.9 & 8.2 & 2.6 \\
\hline 22 & $\mathrm{~N}$ & 2759 & 0.50 & 1362.5 & 0.02 & 160.1 & 524.3 & 167.0 & 0.3 & 0.1 \\
\hline 23 & $\mathrm{~N}$ & 30 & 0.01 & 34.5 & 0.00 & 116.5 & 1081.0 & 158.4 & 2.2 & 0.2 \\
\hline 24 & $\mathrm{~N}$ & 86 & 0.02 & 202.3 & 0.00 & 326.2 & 1529.6 & 319.6 & 3.2 & 0.6 \\
\hline 25 & $\mathrm{~N}$ & 4070 & 0.74 & 196.1 & 0.00 & 22.9 & 185.0 & 22.7 & 0.1 & 0.1 \\
\hline 26 & M & 4422 & 0.81 & 457520.2 & 5.93 & 17.4 & 396726.3 & 10.8 & 35.6 & 0.0 \\
\hline 27 & $\mathrm{~N}$ & 1924 & 0.35 & 325.6 & 0.00 & 7.1 & 725.3 & 7.0 & 0.0 & 0.0 \\
\hline 28 & M & 767 & 0.14 & 21648.8 & 0.28 & 199.1 & 42648.7 & 109.4 & 15.1 & 0.1 \\
\hline 29 & $\mathrm{~N}$ & 407 & 0.07 & 4376.7 & 0.06 & 96.5 & 16361.9 & 111.5 & 2.3 & 0.0 \\
\hline 30 & $\mathrm{H}$ & 971 & 0.18 & 9366.5 & 0.12 & 2387.0 & 10547.3 & 1340.7 & 43.5 & 10.8 \\
\hline
\end{tabular}




\begin{tabular}{|c|c|c|c|c|c|c|c|c|c|c|}
\hline \multicolumn{2}{|c|}{ Classification } & \multicolumn{4}{|c|}{ Air cargo exports, South Africa to EU } & \multicolumn{3}{|c|}{ Value-to-weight (Euro/100kg) } & \multirow{2}{*}{\multicolumn{2}{|c|}{$\begin{array}{l}\text { Time-sensitivity } \\
\text { Air cargo total }\end{array}$}} \\
\hline & & & & & & & & & & \\
\hline HS & Air & $100 \mathrm{~kg}$ & $\%$ & 1000 Euro & $\%$ & Total & Air & Sea & Value & Volume \\
\hline 31 & $\mathrm{~N}$ & 81 & 0.01 & 80.3 & 0.00 & 45.1 & 2041.4 & 42.6 & 2.6 & 0.1 \\
\hline 32 & $\mathrm{~N}$ & 1863 & 0.34 & 3285.2 & 0.04 & 218.0 & 1847.4 & 167.5 & 10.2 & 1.3 \\
\hline 33 & $\mathrm{H}$ & 2858 & 0.52 & 11567.2 & 0.15 & 585.8 & 4061.8 & 419.6 & 29.5 & 4.3 \\
\hline 34 & $\mathrm{~N}$ & 295 & 0.05 & 278.2 & 0.00 & 168.2 & 977.2 & 154.0 & 4.3 & 0.8 \\
\hline 35 & $\mathrm{H}$ & 209 & 0.04 & 3085.9 & 0.04 & 2331.4 & 20504.6 & 394.9 & 84.7 & 12.6 \\
\hline 36 & $\mathrm{H}$ & 99 & 0.02 & 440.4 & 0.01 & 1450.1 & 4850.5 & 746.6 & 47.0 & 16.6 \\
\hline 37 & $\mathrm{H}$ & 94 & 0.02 & 1889.8 & 0.02 & 2088.6 & 18428.6 & 741.8 & 66.8 & 14.4 \\
\hline 38 & $\mathrm{M}$ & 3037 & 0.55 & 11213.5 & 0.15 & 137.3 & 3472.7 & 205.1 & 11.9 & 0.5 \\
\hline 39 & $\mathrm{~N}$ & 3783 & 0.69 & 4386.0 & 0.06 & 173.5 & 1230.3 & 166.1 & 5.5 & 0.8 \\
\hline 40 & $\mathrm{~N}$ & 1286 & 0.23 & 1284.6 & 0.02 & 293.1 & 1036.9 & 279.4 & 1.4 & 0.4 \\
\hline 41 & $M$ & 1439 & 0.26 & 13795.7 & 0.18 & 312.4 & 9655.4 & 237.6 & 20.8 & 0.7 \\
\hline 42 & $\mathrm{H}$ & 1487 & 0.27 & 6578.5 & 0.09 & 3419.6 & 4489.3 & 1825.2 & 76.0 & 58.8 \\
\hline 43 & $\mathrm{H}$ & 126 & 0.02 & 507.5 & 0.01 & 2057.3 & 4094.0 & 930.5 & 63.4 & 35.0 \\
\hline 44 & $\mathrm{~N}$ & 689 & 0.13 & 943.3 & 0.01 & 70.1 & 1300.6 & 70.0 & 1.6 & 0.1 \\
\hline 45 & $\mathrm{H}$ & 63 & 0.01 & 138.8 & 0.00 & 1822.7 & 2302.3 & 1756.9 & 19.0 & 14.3 \\
\hline 46 & $\mathrm{~N}$ & 11 & 0.00 & 22.6 & 0.00 & 150.3 & 2431.5 & 146.9 & 2.2 & 0.2 \\
\hline 47 & $\mathrm{~N}$ & 16 & 0.00 & 3.9 & 0.00 & 54.7 & 165.7 & 54.8 & 0.0 & 0.0 \\
\hline 48 & $\mathrm{~N}$ & 885 & 0.16 & 736.7 & 0.01 & 60.1 & 839.0 & 59.9 & 0.6 & 0.0 \\
\hline 49 & $\mathrm{H}$ & 1801 & 0.33 & 3103.0 & 0.04 & 1014.4 & 1743.9 & 687.3 & 51.6 & 30.6 \\
\hline 50 & $\mathrm{H}$ & 7 & 0.00 & 14.4 & 0.00 & 2394.9 & 2213.8 & 2128.9 & 72.4 & 76.2 \\
\hline 51 & $\mathrm{~L}$ & 493 & 0.09 & 1277.7 & 0.02 & 454.6 & 2530.8 & 446.8 & 1.3 & 0.2 \\
\hline 52 & $\mathrm{M}$ & 394 & 0.07 & 519.4 & 0.01 & 318.5 & 1616.9 & 285.9 & 11.2 & 2.3 \\
\hline 53 & $\mathrm{~N}$ & 4 & 0.00 & 7.9 & 0.00 & 302.1 & 2402.0 & 372.4 & 1.7 & 0.2 \\
\hline 54 & $\mathrm{~N}$ & 533 & 0.10 & 693.5 & 0.01 & 381.5 & 1764.8 & 349.9 & 9.6 & 1.7 \\
\hline 55 & $\mathrm{~N}$ & 188 & 0.03 & 214.8 & 0.00 & 178.5 & 1933.5 & 161.8 & 8.6 & 2.5 \\
\hline 56 & $\mathrm{~N}$ & 403 & 0.07 & 400.7 & 0.01 & 240.5 & 1396.7 & 237.8 & 2.5 & 0.6 \\
\hline 57 & $\mathrm{~L}$ & 233 & 0.04 & 275.9 & 0.00 & 543.5 & 1162.9 & 593.3 & 4.0 & 1.8 \\
\hline 58 & $\mathrm{H}$ & 317 & 0.06 & 1497.5 & 0.02 & 681.2 & 5238.3 & 402.1 & 42.1 & 6.2 \\
\hline 59 & $\mathrm{H}$ & 407 & 0.07 & 1106.1 & 0.01 & 1149.8 & 2651.0 & 738.9 & 47.5 & 22.3 \\
\hline 60 & $\mathrm{H}$ & 121 & 0.02 & 152.3 & 0.00 & 753.4 & 1319.9 & 574.3 & 41.3 & 24.4 \\
\hline 61 & $\mathrm{H}$ & 554 & 0.10 & 2342.9 & 0.03 & 2092.2 & 4216.5 & 1571.4 & 30.8 & 15.0 \\
\hline 62 & $\mathrm{H}$ & 1086 & 0.20 & 3796.5 & 0.05 & 2058.6 & 3495.4 & 1629.3 & 37.6 & 22.6 \\
\hline 63 & $\mathrm{H}$ & 1607 & 0.29 & 5013.7 & 0.06 & 1419.7 & 3131.1 & 698.7 & 54.0 & 24.6 \\
\hline 64 & $\mathrm{H}$ & 205 & 0.04 & 440.5 & 0.01 & 1190.1 & 2212.7 & 991.7 & 23.8 & 13.5 \\
\hline 65 & $\mathrm{H}$ & 179 & 0.03 & 366.2 & 0.00 & 2425.9 & 2898.4 & 1480.7 & 82.4 & 72.6 \\
\hline 66 & $\mathrm{~L}$ & 60 & 0.01 & 92.2 & 0.00 & 568.3 & 1594.7 & 548.0 & 4.0 & 1.5 \\
\hline
\end{tabular}




\begin{tabular}{|c|c|c|c|c|c|c|c|c|c|c|}
\hline \multicolumn{2}{|c|}{ Classification } & \multicolumn{4}{|c|}{ Air cargo exports, South Africa to EU } & \multicolumn{3}{|c|}{ Value-to-weight (Euro/100kg) } & \multirow{2}{*}{\multicolumn{2}{|c|}{$\begin{array}{c}\text { Time-sensitivity } \\
\text { Air cargo total }\end{array}$}} \\
\hline & & & & & & & & & & \\
\hline HS & Air & $100 \mathrm{~kg}$ & $\%$ & 1000 Euro & $\%$ & Total & Air & Sea & Value & Volume \\
\hline 67 & $\mathrm{H}$ & 227 & 0.04 & 697.4 & 0.01 & 2916.6 & 4066.1 & 1733.3 & 80.7 & 60.7 \\
\hline 68 & M & 2683 & 0.49 & 13531.1 & 0.18 & 270.8 & 5434.3 & 131.1 & 37.0 & 2.4 \\
\hline 69 & $\mathrm{H}$ & 2010 & 0.37 & 3520.9 & 0.05 & 456.6 & 1756.0 & 294.5 & 39.8 & 10.5 \\
\hline 70 & $\mathrm{~N}$ & 494 & 0.09 & 534.3 & 0.01 & 190.2 & 1127.1 & 190.5 & 1.4 & 0.2 \\
\hline 71 & $\mathrm{H}$ & 2453 & 0.45 & 6043974.4 & 78.27 & 413969.7 & 2453985.6 & 3696.2 & 89.6 & 15.7 \\
\hline 72 & $\mathrm{~N}$ & 12966 & 2.37 & 1300.5 & 0.02 & 86.6 & 275.3 & 81.5 & 0.1 & 0.1 \\
\hline 73 & $\mathrm{~N}$ & 4072 & 0.74 & 3754.2 & 0.05 & 129.4 & 938.8 & 121.5 & 5.7 & 0.8 \\
\hline 74 & $\mathrm{~L}$ & 1547 & 0.28 & 1091.0 & 0.01 & 437.0 & 1497.2 & 440.2 & 0.9 & 0.6 \\
\hline 75 & $\mathrm{~L}$ & 138 & 0.03 & 356.0 & 0.00 & 1109.7 & 4163.3 & 1079.5 & 2.5 & 0.8 \\
\hline 76 & $\mathrm{~N}$ & 3819 & 0.70 & 2818.9 & 0.04 & 232.1 & 791.1 & 236.5 & 1.4 & 0.4 \\
\hline 78 & $\mathrm{~N}$ & 11 & 0.00 & 35.7 & 0.00 & 166.8 & 2995.8 & 152.6 & 6.5 & 0.7 \\
\hline 79 & $\mathrm{~N}$ & 7 & 0.00 & 4.4 & 0.00 & 193.0 & 472.2 & 177.1 & 2.4 & 1.7 \\
\hline 80 & $\mathrm{H}$ & 4 & 0.00 & 20.0 & 0.00 & 511.1 & 6184.7 & 397.8 & 18.7 & 2.7 \\
\hline 81 & $\mathrm{~N}$ & 593 & 0.11 & 3008.4 & 0.04 & 421.8 & 5162.7 & 418.9 & 8.8 & 0.7 \\
\hline 82 & $\mathrm{H}$ & 2943 & 0.54 & 13041.3 & 0.17 & 2676.1 & 4454.8 & 1159.7 & 75.8 & 46.0 \\
\hline 83 & $\mathrm{H}$ & 1060 & 0.19 & 1699.7 & 0.02 & 677.7 & 1844.2 & 531.4 & 28.3 & 10.9 \\
\hline 84 & $\mathrm{H}$ & 80261 & 14.66 & 406064.0 & 5.26 & 2047.5 & 5083.5 & 1584.9 & 21.5 & 8.7 \\
\hline 85 & $\mathrm{H}$ & 11701 & 2.14 & 105957.4 & 1.37 & 1669.7 & 9458.5 & 1084.6 & 33.5 & 6.1 \\
\hline 86 & $\mathrm{~N}$ & 377 & 0.07 & 275.3 & 0.00 & 351.6 & 739.0 & 342.2 & 5.9 & 2.6 \\
\hline 87 & $\mathrm{~L}$ & 17323 & 3.17 & 25575.0 & 0.33 & 901.0 & 1560.3 & 818.4 & 3.1 & 1.8 \\
\hline 88 & $\mathrm{H}$ & 1368 & 0.25 & 60677.7 & 0.79 & 37791.3 & 43454.4 & 7923.2 & 86.4 & 74.4 \\
\hline 89 & $\mathrm{~L}$ & 58 & 0.01 & 429.2 & 0.01 & 2755.5 & 5610.4 & 2342.1 & 2.3 & 1.0 \\
\hline 90 & $\mathrm{H}$ & 2259 & 0.41 & 60367.6 & 0.78 & 10289.9 & 27281.6 & 2116.4 & 76.7 & 29.4 \\
\hline 91 & $\mathrm{H}$ & 10 & 0.00 & 221.4 & 0.00 & 16965.7 & 22739.6 & 2128.9 & 74.8 & 58.1 \\
\hline 92 & $\mathrm{H}$ & 28 & 0.01 & 81.1 & 0.00 & 1976.1 & 3488.1 & 1112.5 & 52.4 & 34.4 \\
\hline 93 & M & 277 & 0.05 & 913.6 & 0.01 & 422.9 & 6833.0 & 368.1 & 13.6 & 1.7 \\
\hline 94 & $\mathrm{H}$ & 49424 & 9.03 & 249053.8 & 3.23 & 2301.8 & 5127.9 & 416.5 & 90.4 & 43.6 \\
\hline 95 & $\mathrm{H}$ & 480 & 0.09 & 1699.4 & 0.02 & 992.6 & 3512.5 & 805.0 & 31.4 & 8.8 \\
\hline 96 & $\mathrm{H}$ & 535 & 0.10 & 1069.2 & 0.01 & 721.7 & 2270.5 & 546.2 & 29.9 & 10.8 \\
\hline 97 & $\mathrm{H}$ & 1262 & 0.23 & 7347.5 & 0.10 & 2384.8 & 5930.8 & 840.0 & 71.5 & 28.8 \\
\hline
\end{tabular}

(Note) calculations are based on averages of the period of 2005 to 2010. Time sensitivity is calculated as the share of air cargo transport (value or volume) in total transport (value or volume). See Appendix 4 for a list of products by HS classification.

(Source) Calculation based on Eurostat (2012a,b). 


\section{Appendix 2: Check-in South Africa}

(Products with high value-to-weight ratios in the average Airplane Bound to the EU)

\begin{tabular}{|c|c|c|c|c|c|c|c|c|c|}
\hline & \multicolumn{3}{|c|}{ Value-to-weight } & \multicolumn{4}{|c|}{ Air cargo } & \multicolumn{2}{|c|}{ Time-sensitivity } \\
\hline & Total & Air cargo & Sea cargo & & & & & Air cars & go total \\
\hline HS group & & ro $/ 100 \mathrm{~kg}$ & & Euro & $\%$ & $100 \mathrm{~kg}$ & $\%$ & $\%$ value & $\%$ weight \\
\hline Total & 41.4 & 14175.7 & 21.8 & 7721790993 & 100.00 & 547299 & 100.0 & 37.8 & 0.1 \\
\hline 71 & 413969.7 & 2453985.6 & 3696.2 & 6043974368 & 78.27 & 2453 & 0.45 & 89.6 & 15.7 \\
\hline 88 & 37791.3 & 43454.4 & 7923.2 & 60677709 & 0.79 & 1368 & 0.25 & 86.4 & 74.4 \\
\hline 91 & 16965.7 & 22739.6 & 2128.9 & 221422 & 0.00 & 10 & 0.00 & 74.8 & 58.1 \\
\hline 90 & 10289.9 & 27281.6 & 2116.4 & 60367601 & 0.78 & 2259 & 0.41 & 76.7 & 29.4 \\
\hline 42 & 3419.6 & 4489.3 & 1825.2 & 6578532 & 0.09 & 1487 & 0.27 & 76.0 & 58.8 \\
\hline 67 & 2916.6 & 4066.1 & 1733.3 & 697443 & 0.01 & 227 & 0.04 & 80.7 & 60.7 \\
\hline 89 & 2755.5 & 5610.4 & 2342.1 & 429154 & 0.01 & 58 & 0.01 & 2.3 & 1.0 \\
\hline 82 & 2676.1 & 4454.8 & 1159.7 & 13041314 & 0.17 & 2943 & 0.54 & 75.8 & 46.0 \\
\hline 01 & 2525.4 & 3000.5 & 2128.9 & 440557 & 0.01 & 148 & 0.03 & 78.6 & 67.8 \\
\hline 65 & 2425.9 & 2898.4 & 1480.7 & 366237 & 0.00 & 179 & 0.03 & 82.4 & 72.6 \\
\hline 50 & 2394.9 & 2213.8 & 2128.9 & 14373 & 0.00 & 7 & 0.00 & 72.4 & 76.2 \\
\hline 30 & 2387.0 & 10547.3 & 1340.7 & 9366451 & 0.12 & 971 & 0.18 & 43.5 & 10.8 \\
\hline 97 & 2384.8 & 5930.8 & 840.0 & 7347488 & 0.10 & 1262 & 0.23 & 71.5 & 28.8 \\
\hline 35 & 2331.4 & 20504.6 & 394.9 & 3085856 & 0.04 & 209 & 0.04 & 84.7 & 12.6 \\
\hline 94 & 2301.8 & 5127.9 & 416.5 & 249053753 & 3.23 & 49424 & 9.03 & 90.4 & 43.6 \\
\hline 61 & 2092.2 & 4216.5 & 1571.4 & 2342913 & 0.03 & 554 & 0.10 & 30.8 & 15.0 \\
\hline 37 & 2088.6 & 18428.6 & 741.8 & 1889756 & 0.02 & 94 & 0.02 & 66.8 & 14.4 \\
\hline 62 & 2058.6 & 3495.4 & 1629.3 & 3796473 & 0.05 & 1086 & 0.20 & 37.6 & 22.6 \\
\hline 43 & 2057.3 & 4094.0 & 930.5 & 507452 & 0.01 & 126 & 0.02 & 63.4 & 35.0 \\
\hline 84 & 2047.5 & 5083.5 & 1584.9 & 406063967 & 5.26 & 80261 & 14.66 & 21.5 & 8.7 \\
\hline Top 20 & - & - & - & 6870262819 & 88.97 & 145125 & 26.52 & - & \\
\hline
\end{tabular}

(Note) The average airplane is based on averages of the period of 2005 to 2010. Time sensitivity is calculated as the share of air cargo transport (value or volume) out of total transport (value or volume). See Appendixes 1 and 4 for detailed information on product categories.

(Source) Calculation based on Eurostat (2012a,b). 


\section{Appendix 3: Cargo Inspection at Departure}

(Products by loading weight of an average Airplane from South Africa to the EU)

\begin{tabular}{|c|c|c|c|c|c|c|c|c|c|}
\hline \multirow[b]{3}{*}{$\begin{array}{l}\text { HS } \\
\text { group }\end{array}$} & \multicolumn{4}{|c|}{ Air cargo } & \multicolumn{2}{|c|}{ Time-sensitivity } & \multicolumn{3}{|c|}{ Value-to-Weight } \\
\hline & & & & & Air carg & o/total & Total & $\begin{array}{c}\text { Sea } \\
\text { cargo }\end{array}$ & Air cargo \\
\hline & $100 \mathrm{~kg}$ & $\%$ & Euro & $\%$ & $\%$ weight & $\%$ value & \multicolumn{3}{|c|}{ Euro $/ 100 \mathrm{~kg}$} \\
\hline Total & 547299 & 100.00 & 7721790993 & 100.00 & 0.1 & 37.8 & 41.4 & 21.8 & 14175.7 \\
\hline 03 & 144916 & 26.48 & 58978532 & 0.76 & 24.9 & 28.2 & 356.6 & 339.2 & 403. \\
\hline 08 & 94612 & 17.29 & 30273032 & 0.39 & 0.8 & 2.7 & 98.0 & 90.5 & 322.7 \\
\hline 84 & 80261 & 14.66 & 406063967 & 5.26 & 8.7 & 21.5 & 2047.5 & 1584.9 & 5083.5 \\
\hline 94 & 49424 & 9.03 & 249053753 & 3.23 & 43.6 & 90.4 & 2301.8 & 416.5 & 5127.9 \\
\hline 06 & 33048 & 6.04 & 17687290 & 0.23 & 39.7 & 45.8 & 467.3 & 383.1 & 551.6 \\
\hline 87 & 17323 & 3.17 & 25574957 & 0.33 & 1.8 & 3.1 & 901.0 & 818.4 & 1560.3 \\
\hline 07 & 16739 & 3.06 & 6481197 & 0.08 & 9.6 & 38.3 & 93.7 & 59.1 & 387. \\
\hline 72 & 12966 & 2.37 & 1300501 & 0.02 & 0.1 & 0.1 & 86.6 & 81.5 & 275.3 \\
\hline 85 & 11701 & 2.14 & 105957392 & 1.37 & 6.1 & 33.5 & 1669.7 & 1084.6 & 9458.5 \\
\hline 02 & 8407 & 1.54 & 8517570 & 0.11 & 25.8 & 31.4 & 832.9 & 752.3 & 1014.5 \\
\hline 26 & 4422 & 0.81 & 457520230 & 5.93 & 0.0 & 35.6 & 17.4 & 10.8 & 396726.3 \\
\hline 73 & 4072 & 0.74 & 3754222 & 0.05 & 0.8 & 5.7 & 129.4 & 121.5 & 938.8 \\
\hline Top ten & 348206 & 63.62 & 716044923 & 9.27 & - & - & - & - & \\
\hline
\end{tabular}

(Note) The top ten excludes HS84 and HS94 because they show up in Appendix 2 as well. The average airplane is based on averages for the period of 2005 to 2010. Time sensitivity is calculated as the share of air cargo transport (value or volume) out of total transport (value or volume). See Appendixes 1 and 4 for detailed information on product categories.

(Source) Calculation based on Eurostat (2012a,b). 


\section{Appendix 4: List of Products according to Air Cargo Relevance}

Non-air relevance (low value-to-weight and low time-sensitivity):

08 edible fruits and nuts, 09 coffee, tea, and spices, 10 cereals, 11 products of the milling industry, 12 oil seeds and oleaginous fruits, grains, and plants, 14 vegetable plaiting materials, 16 preparations of meat, fish, or crustaceans, 19 preparations of cereals and flour, 20 preparations of vegetables, fruit, nuts, and plants, 21 miscellaneous edible preparations, 22 beverages, spirits, and vinegar, 24 tobacco, 25 salt, sulphur, earths and stones, plastering materials, lime, and cement, 27 mineral fuels, oils, and products of their distillation, 29 organic chemicals, 31 fertilizers, 32 tanning or dyeing extracts and their derivatives, 34 Soap, organic surface-active agents, washing preparations, lubricating preparations, 39 Plastics and articles thereof, 40 rubber and articles thereof, 44 wood and articles thereof, 46 manufactures of straw, esparto, or other plaiting materials, basketware, and wickerwork, 47 pulp of wood or of other fibrous cellulosic material, 48 paper and paperboard, 53 other vegetable textile fibres, 54 man-made filaments, 55 man-made staple fibres, 56 wadding, felt, and nonwovens; special yarns; twine and cordage, 70 glass and glassware, 72 iron and steel, 73 articles of iron or steel, 76 aluminium and articles thereof, 78 lead and articles thereof, 79 zinc and articles thereof, 81 other base metals and cermets, and 86 railway or tramway locomotives, rolling-stock, and parts.

\section{Low air relevance (high value-to-weight and low time-sensitivity):}

04 Dairy produce, birds' eggs, and natural honey, 13 lac, gums, resins, and other vegetable saps and extracts, 18 cocoa and cocoa preparations, 51 wool, animal hair, horsehair yarn, and woven fabrics, 57 carpets and other textile floor coverings, 66 umbrellas, sun umbrellas, and walking-sticks, 74 copper and articles thereof, 75 nickel and articles thereof, 87 vehicles other than railways or tramways, and 89 ships and boats.

Medium air relevance (low value-to-weight and high time-sensitivity):

03 Fish and crustaceans, 07 edible vegetables and certain roots and tubers, 17 sugars and sugar confectionery, 26 ores, slag, and ash, 28 inorganic chemicals, 38 miscellaneous chemical products, 41 raw hides and skins (other than furskins) and leather, 52 cotton, 68 articles of stone, plaster, cement, and asbestos, and 93 arms and ammunition. 
High air relevance (high value-to-weight and high time-sensitivity):

01 Live animals, 02 meat and edible meat offal, 05 products of animal origin, 06 live trees and other plants, 30 pharmaceutical products, 33 Essential oils and resinoids, perfumery, and cosmetic, 35 albuminoidal substances, modified starches, glues, and enzymes, 36 explosives and pyrotechnic products, 37 photographic or cinematographic goods, 42 articles of leather, saddlery and harness, 43 Furskins and artificial fur, 45 Cork and articles of cork, 49 printed books and newspapers, 50 silk, 58 special woven fabrics, 59 impregnated, coated, covered, or laminated textile fabrics, 60 knitted or crocheted fabrics, 61+62 articles of apparel and clothing accessories, 64 other made up textile articles, 65 footwear and gaiters, 67 prepared feathers and artificial flowers, 69 ceramic products, 71 natural or cultured pearls, precious or semi-precious stones, precious metals, metals clad with precious metal, and articles thereof, imitation jewellery, and coins, 80 tin and articles thereof, 82 tools, implements, and cutlery, 83 miscellaneous articles of base metal, 84 nuclear reactors, boilers, machinery, and mechanical appliances, 85 electrical machinery and equipment and parts thereof, sound recorders and reproducers, and television image and sound recorders and reproducers, 88 aircraft, spacecraft, and parts thereof, 90 optical, photographic, cinematographic, measuring, checking, precision, medical or surgical instruments and apparatus, and parts and accessories thereof, 91 clocks and watches, 92 musical instruments, 94 furniture, bedding, and mattresses, 95 toys, games, and sports requisites, 96 miscellaneous manufactured articles, and 97 works of art, collectors' pieces, and antiques.

(Note) Products according to harmonized system (HS) classification.

(Source) own compilation based on Eurostat (2012a,b). 


\section{Appendix 5:}

Air Cargo Intensity of South Africa's Trade with Industrialized Countries

\begin{tabular}{|c|c|c|c|c|c|c|c|c|c|}
\hline & \multicolumn{3}{|c|}{ South Africa-EU } & \multicolumn{3}{|c|}{ South Africa - US } & \multicolumn{3}{|c|}{ South Africa - Japan } \\
\hline & 2005 & 2010 & $\begin{array}{c}\text { Growth } \\
2005 \sim 10\end{array}$ & 2005 & 2010 & $\begin{array}{c}\text { Growth } \\
2005 \sim 10\end{array}$ & 2005 & 2010 & $\begin{array}{c}\text { Growth } \\
2005 \sim 10\end{array}$ \\
\hline & \multicolumn{9}{|c|}{ Exports } \\
\hline Total & 16,930 & 18,667 & 10.3 & 4,893 & 7,060 & 44.3 & 5,149 & 6,425 & 24.8 \\
\hline Non-air & 43.5 & 37.8 & -4.1 & 32.0 & 24.1 & 8.4 & 28.1 & 22.7 & 1.0 \\
\hline Low-air & 8.2 & 13.2 & 77.3 & 7.2 & 27.6 & 454.0 & 23.7 & 8.4 & -56.0 \\
\hline Medium-air & 10.6 & 14.2 & 47.7 & 12.8 & 10.1 & 13.7 & 11.3 & 16.0 & 76.9 \\
\hline \multirow[t]{2}{*}{ High-air } & 37.7 & 34.7 & 1.6 & 48.0 & 38.3 & 14.9 & 36.8 & 52.9 & 79.0 \\
\hline & \multicolumn{9}{|c|}{ Imports } \\
\hline Total & 18,532 & 22,741 & 22.7 & 4,417 & 5,730 & 35.9 & 2,385 & 3,100 & 30.0 \\
\hline Non-air & 20.8 & 27.2 & 60.8 & 20.1 & 24.4 & 65.1 & 11.9 & 12.5 & 36.3 \\
\hline Low-air & 17.6 & 15.2 & 5.8 & 9.8 & 10.8 & 48.6 & 35.9 & 39.0 & 41.4 \\
\hline Medium-air & 3.9 & 4.1 & 30.6 & 5.7 & 5.7 & 35.8 & 1.9 & 2.4 & 66.1 \\
\hline High-air & 57.7 & 53.5 & 13.6 & 64.4 & 59.2 & 24.9 & 50.4 & 46.1 & 19.0 \\
\hline
\end{tabular}

(Note) Total trade figures in millions of USD excluding exports and imports of other commodities n.e.s. (HS 99). See Appendixes 1 and 4 for detailed information on product categories.

(Source) Calculation based on ITC (2012).

Appendix 6: Air Cargo Intensity of South Africa's Trade with BRICs

\begin{tabular}{|c|c|c|c|c|c|c|c|c|c|}
\hline & \multicolumn{3}{|c|}{ South Africa - Brazil } & \multicolumn{3}{|c|}{ South Africa - China } & \multicolumn{3}{|c|}{ South Africa - India } \\
\hline & 2005 & 2010 & $\begin{array}{l}\text { Growth } \\
2005 \sim 10\end{array}$ & 2005 & 2010 & $\begin{array}{c}\text { Growth } \\
2005 \sim 10\end{array}$ & 2005 & 2010 & $\begin{array}{c}\text { Growth } \\
2005 \sim 10\end{array}$ \\
\hline & \multicolumn{9}{|c|}{ Exports } \\
\hline Total & 318 & 717 & 125.6 & 1,369 & 8,132 & 494.2 & 1,170 & 2,981 & 154.7 \\
\hline Non-air & 69.2 & 70.0 & 128.3 & 36.9 & 24.2 & 289.1 & 40.4 & 77.4 & 388.0 \\
\hline Low-air & 1.9 & 0.7 & -19.6 & 10.2 & 5.4 & 213.2 & 2.0 & 1.7 & 117.8 \\
\hline Medium-air & 12.0 & 10.7 & 101.1 & 47.9 & 66.1 & 718.7 & 17.9 & 15.4 & 120.0 \\
\hline \multirow[t]{2}{*}{ High-air } & 16.9 & 18.6 & 148.4 & 4.9 & 4.4 & 426.2 & 39.7 & 5.4 & -65.4 \\
\hline & \multicolumn{9}{|c|}{ Imports } \\
\hline Total & 956 & 1,048 & 9.6 & 4,926 & 11,460 & 132.6 & 1,075 & 2,813 & 161.7 \\
\hline Non-air & 32.4 & 29.5 & -0.4 & 15.6 & 18.4 & 173.3 & 42.9 & 50.1 & 206.2 \\
\hline Low-air & 14.3 & 11.9 & -8.9 & 2.9 & 3.6 & 190.9 & 19.3 & 14.8 & 100.3 \\
\hline Medium-air & 7.6 & 13.3 & 92.3 & 3.7 & 3.7 & 128.5 & 7.4 & 4.2 & 49.1 \\
\hline High-air & 45.7 & 45.4 & 8.8 & 77.7 & 74.4 & 122.5 & 30.5 & 30.9 & 165.4 \\
\hline
\end{tabular}

(Note) Total trade figures in millions of USD excluding exports and imports of other commodities n.e.s. (HS 99). See Appendixes 1 and 4 for detailed information on product categories.

(Source) Calculation based on ITC (2012). 